\title{
Competition in the Presence of Individual Demand Uncertainty
}

\author{
Marc Möller*
}

\author{
Makoto Watanabe ${ }^{\dagger}$
}

\begin{abstract}
This paper sheds light on an empirical controversy about the effect of competition on price discrimination. We propose a model in which consumers learn their preferences over time and show that firms offer advance purchase discounts. Consumers choose between an early (uninformed) purchase at a low price and a late (informed) purchase at a high price. Competing firms offer higher discounts to secure a large market share in advance. Competition decreases welfare and may affect consumers negatively. The empirical finding, that competition may influence price dispersion positively or negatively, can be explained by differences in the level of demand uncertainty.
\end{abstract}

Keywords: Competition, Price Discrimination, Individual Demand Uncertainty, Advance Purchase Discounts.

JEL: D43, D80, L13.

*Department of Economics, University of Bern, Schanzeneckstrasse 1, 3001 Bern, Switzerland. Email: marc.moeller@vwi.unibe.ch, Tel.: +41-(0)31631-8078, Fax: +41-(0)31631-3783 .

${ }^{\dagger}$ Department of Economics, FEWEB, VU University Amsterdam, Tinbergen Institute, Address: Department of Economics, VU Amsterdam, De Boelelaan 1105, NL-1081 HV Amsterdam, The Netherlands, makoto.wtnb@gmail.com, Tel.: +31-20598-6030, Fax: +31-20598-9870. 


\section{Introduction}

Merger policy and price regulation are amongst the most frequently used market interventions. Understanding the interaction between industry structure and pricing is therefore of utmost importance. In particular, the effect of competition on a firm's ability to price discriminate its customers constitutes a crucial element of any welfare analysis.

In recent years an empirical controversy has developed concerning the relation between market concentration and price dispersion in differentiated product markets, with a focus on airline pricing. Using a cross sectional approach, Borenstein and Rose (1994) and Stavins (1996) find that routes characterized by higher levels of competition exhibit more price dispersion. ${ }^{1}$ More recent studies contradict these earlier findings. Gerardi and Shapiro (2009) and Gaggero and Piga (2011) employ panel data and find a negative effect of competition on fare dispersion. Latest evidence even suggests the existence of a non-monotonic relationship (Dai et al. (2014)).

The common explanation for a negative relation between competition and price dispersion is based on "traditional microeconomic theory". While a monopolist might be able to price discriminate between groups of buyers with different demand elasticities, a perfectly competitive industry is characterized by marginal cost pricing. Extrapolating between these polar cases, price dispersion should therefore be decreasing in the number of firms. This view has been challenged by Borenstein (1985) and Holmes (1989) who show that in an oligopolistic market, a consumer's firm level elasticity of demand can be decomposed into an industry-demand elasticity, measuring his willingness to participate in the market, and a cross-price elasticity, determining his propensity to switch supplier. If firms discriminate consumers with respect to the cross-price elasticity, then competition will reduce the low prices charged to high elasticity consumers even further, while relatively high prices can be maintained for those who are reluctant to switch. This "brand-loyalty effect" therefore provides an explanation for a positive relation between competition and price dispersion. ${ }^{2}$

In order to account, not only, for the range of observable prices, but also the frequency with which different prices are charged, most empirical studies employ the Gini coefficient as a measure of price discrimination. This is important, since the existence of a wide price range does not rule out the possibility that a uniform price is charged to most of

\footnotetext{
${ }^{1}$ Further evidence for a positive relation between competition and price discrimination has been documented for other industries. See Asplund et al. (2008) for regional newspapers and Busse and Rysman (2005) for Yellow Pages advertising.

${ }^{2}$ Dana (1999) offers an alternative explanation based on price rigidity and aggregate demand uncertainty.
} 
the consumers. In this paper we propose a simple model of intertemporal (second degree) price discrimination in which market segmentation is determined endogenously. We show that, although competition has a positive effect on the range of prices offered, the effect on the Gini coefficient of price dispersion can go either way.

Our argument is based on the observation that in many markets consumers are uncertain about their individual preferences. For example, at the time of purchase, a consumer choosing between a Thursday flight and a Friday flight may not know (perfectly) which product he will ultimately prefer. Further examples include the advance booking of theater tickets, pre-orders of music albums, the acquisition of wine for long-term storage, or the registration for conferences and sports events.

What consumers typically do know is the intensity with which they will prefer one product over the other. For example, business travelers attach a higher importance to traveling on the correct date than leisure travelers. We propose a natural way in which both features can be incorporated into Hotelling's model of product differentiation. For this purpose we add an advance purchase period in which each consumer knows the intensity of his preferences (his distance form the center of the Hotelling line), but receives only an imperfect signal about the identity of his preferred product (his direction). The level of demand uncertainty (the signals' precision) and the degree of product differentiation (the unit cost of transportation) constitute the key parameters of the model.

We show that in equilibrium firms implement advance purchase discounts (APDs) to screen consumers according to their intensity of preferences. Consumers with weak preferences (leisure travelers, located close to the center) are induced to make an uninformed purchase at a low price, whereas consumers with strong preferences (business travelers, located close to the extremes) postpone their purchase until their demand uncertainty has been resolved. ${ }^{3}$

A comparison with the (multi-product) monopolistic benchmark reveals that competition leads to larger APDs. However, while having a positive effect on the range of observed prices, competition also leads to a less pronounced segmentation of the market. This is because the firms' incentive to capture those consumers in advance, who might become their rival's customers in the future, leads to a large fraction of consumers being served at a discount. ${ }^{4}$ We show that the overall effect on the Gini coefficient of price dis-

\footnotetext{
${ }^{3}$ This behavioral pattern is consistent with an in-flight survey conducted by the US Office of Travel and Tourism Industries, showing that consumers, who choose "price" as their main reason for their choice of carrier, book, on average, one week earlier and pay $31 \%$ less than those choosing "convenience of schedule". For a description see http://tinet.ita.doc.gov/research/programs/ifs/description.html.

${ }^{4}$ This is similar to the occurrence of customer poaching in markets with switching costs (Chen (1997), Villas-Boas (1999), Fudenberg and Tirole (2000)) with the difference that consumers are captured ex ante
} 
persion is positive if and only if the level of demand uncertainty is high or the degree of product differentiation is low. In contrast, when consumers differentiate strongly between products and are relatively certain about their preferred option, competition leads to a decrease in price dispersion.

Interpreting product differentiation and demand uncertainty as route specific features, this result resonates well with Gerardi and Shapiro's (2009) finding that the inclusion of route fixed effects in the panel regressions makes the coefficient on competition change its sign. In particular, since consumers are more heterogeneous when product differentiation is high and demand uncertainty is low, our result is consistent with their finding that the negative effect of competition on price discrimination is pronounced for routes characterized by a relatively heterogeneous customer base.

We also explore the welfare effects of competition and price discrimination. In our setup, an increase in the fraction of advance purchases implies a greater risk of mismatch between preferences and product characteristics. Due to the absence of quantity effects in the Hotelling framework, we thus find that competition leads to a reduction in total surplus. With respect to consumer surplus, the increased mismatch might be compensated by a decrease in prices. We show that competition increases aggregate consumer surplus if and only if the degree of product differentiation is low. If the degree of product differentiation is high, competition increases the surplus of consumers with weak preferences (leisure travelers) but decreases the surplus for consumers with strong preferences (business travelers), due to an increase in spot prices. This result is consistent with evidence provided by Borenstein (1989) showing that more competitive airline routes are characterized by lower 20th percentile fares but higher 80th percentile fares.

In our framework, price regulation, in form of a ban on APDs, has a positive effect on total surplus, independently of market structure. However, market structure determines whether it is firms or consumers who benefit from such a ban. In particular, banning APDs leads to an increase in consumer surplus and a decrease in profits under monopoly but has the opposite effect under competition. Under competition, the firms' ability to price discriminate intertemporally puts additional downward pressure on prices, making APDs desirable from the consumers' point of view. This provides us with an argument for why merger policy and price regulation should go hand in hand.

A final contribution of the paper, is to highlight a novel relation between market structure and individual demand uncertainty. We show that in the face of competition, profits are decreasing in the level of uncertainty whereas for a monopolist, profits are rather than ex post. 
increasing. This implies that the incentives for monopolization are stronger in markets with more uncertainty.

We close this section with a discussion of the related literature. The existing literature on intertemporal price discrimination with individual demand uncertainty lacks the analysis of competition: DeGraba (1995), Courty and Li (2000), Courty (2003), Möller and Watanabe (2010), and Nocke, Peitz, and Rosar (2011) all consider the monopolist's problem. ${ }^{5}$

APDs have been derived as optimal selling mechanisms in other settings. Dana (1998) derives an APD for a perfectly competitive industry characterized by aggregate demand uncertainty. His analysis suggests that market power may not be necessary to explain the observation of an APD. Firms use APDs in order to reduce the risk of holding unutilized capacity. Similarly, Gale and Holmes (1993) show that an airline may use APDs to divert consumers from a peak period where demand exceeds capacity to an off-peak period. In our setting, aggregate demand is certain and capacity is neither restricted nor costly. The sole purpose of an APD is the extraction of consumer (information) rents.

Since APDs influence the timing of sales and hence the amount of information that is available to consumers at the time of purchase, our model also relates to the literature on information disclosure in market settings. Lewis and Sappington (1994) and Bar Isaac et al. (2010) consider the issue of whether a monopolist should provide buyers with information about their valuation of his product. Although the level of demand uncertainty is exogenous in our model, the fact that monopoly profits are increasing in this parameter whereas duopoly profits are decreasing suggests that market structure may have a crucial influence on the amount of information a market is supplied with.

Finally, our model allows the interpretation of the consumers' timing of purchase as a choice between a refundable high price ticket and a non-refundable low price ticket. This relates our model to the literature on non-linear pricing in which firms compete by offering quality-price menus (see Stole (1995), Armstrong and Vickers (2001), and Rochet and Stole (2002)). We provide a detailed comparison with this literature after the presentation of our main results (Propositions 3-5).

\footnotetext{
${ }^{5}$ An exception is Gale (1993) who features a duopoly but assumes that products are homogeneous ex ante with the consequence that price equals marginal cost in the advance purchase period. When products are differentiated not only ex post but also ex ante, the effect of competition on the sellers' ability to screen buyers intertemporally is still unclear.
} 


\section{Model}

We consider a market with two differentiated products $A$ and $B$, e.g. a Thursday flight and a Friday flight between identical destinations. The products are located at the extremes of a Hotelling line $[0,1]$. There is a continuum of consumers with mass 1 . Preferences are characterized by a location $\hat{x} \in[0,1]$ along the Hotelling line. Consumers have unit demands and derive utility $s>0$ from consuming either product. They incur a disutility equal to $t$ times the distance between their location and the product of their choice. ${ }^{6}$ The parameter $t>0$ measures the degree of product differentiation. The unit cost of production is constant and identical across products. For simplicity, we normalize unit costs to zero. ${ }^{7}$

There are two periods. Period 1 constitutes an advance selling period in which consumers face individual demand uncertainty. Period 2 constitutes the consumption period in which all demand uncertainty has been resolved. We assume that each firm $i \in\{A, B\}$ can commit to a price schedule $\left(p_{1, i}, p_{2, i}\right)$ where $p_{1, i}$ and $p_{2, i}$ denote the firm's prices in period 1 and 2 respectively. ${ }^{8}$ In order to focus on the effects of demand uncertainty, we abstract from discounting.

Our main assumption is that each consumer knows the intensity with which he differentiates between products $A$ and $B$ but is uncertain about his preferred option. For example, a traveler may very well be able to judge the importance of flying on the correct date, but may not know the correct date in advance. We capture this by assuming that in period 1, a consumer knows that he is located at one of two possible locations $\hat{x} \in\left\{\frac{1}{2}-\frac{\sigma}{2}, \frac{1}{2}+\frac{\sigma}{2}\right\}$. The intensity with which the consumer distinguishes between products $A$ and $B$ is given by $\sigma \in[0,1]$ and constitutes the consumer's private knowledge. A consumer with $\sigma=0$ is completely indifferent between products $A$ and $B$ whereas for a consumer with $\sigma=1$, the disutility from consuming the "wrong product" is maximal and given by $t$. For example, flying on Thursday rather than Friday may imply a considerable degree of inconvenience for business travelers whereas leisure travelers may care less.

In period 1, each consumer privately receives a signal $S \in\{A, B\}$ about the identity of his preferred product. The signal's precision, i.e. the probability with which the signal

\footnotetext{
${ }^{6}$ Our main results remain valid when transportation costs are quadratic rather than linear. For details see Section 5.

${ }^{7}$ The case of positive unit costs is discussed in Section 5.

${ }^{8}$ For example, the organizers of conferences or sport events often commit to prices by publishing a schedule of registration fees. In other cases, e.g. airlines, commitment is a result of the repeated nature of transactions. In the absence of commitment, firms face a time consistency problem, similar to the one in the durable goods literature (see e.g. Bulow (1982)).
} 
reveals the consumer's true preference, is given by $\gamma \in\left(\frac{1}{2}, 1\right)$. The parameter $\gamma$ measures the level of individual demand uncertainty and is the same for all consumers. For $\gamma \rightarrow \frac{1}{2}$, consumers face complete uncertainty whereas for $\gamma \rightarrow 1$ preferences are certain.

For each consumer, the values of $\sigma$ and $S$, determine a point $x \in[0,1]$ on the Hotelling line where the consumer is most likely to be located. $x$ will be denoted as the consumer's type and is given by $x=\frac{1}{2}-\frac{\sigma}{2}$ for $S=A$ and $x=\frac{1}{2}+\frac{\sigma}{2}$ for $S=B$. We assume that all $\sigma \in[0,1]$ are equally likely and that for each $\sigma$, the mass of consumers who receive signal $A$ is the same as the mass of consumers who receive signal $B$. These assumptions imply that types are uniformly distributed across $[0,1]$.

In our setting, consumers who postpone their purchase until period 2 insure themselves against the possibility of a sub-optimal product choice. Alternatively, consumers could achieve such insurance by either buying both products in period 1 or by purchasing the second product in period 2 in case of a mismatch. We rule out these alternative forms of insurance. In particular, we assume that each consumer can purchase at most one product. Without this assumption, consumers will refrain from multiple purchases in equilibrium when prices are sufficiently high. For details see our discussion in Section 5.

Finally, we make the standard covered market assumption that $s$ is sufficiently large to make all consumers purchase one unit in equilibrium. We will see that this requires

Assumption 1 Covered market: $s>\underline{s} \equiv \frac{9 \gamma-3}{-8 \gamma^{2}+14 \gamma-2} t$.

In the following we first consider the monopoly case in which both products are offered by a single firm. Subsequently, we analyze the duopoly case where products are offered by two different firms. The comparison between monopoly and duopoly will allow us to shed light on the effect of competition on (intertemporal) price discrimination. It is a particularly relevant comparison in light of the empirical studies of the airline industry where market concentration is extremely high. ${ }^{9}$

\section{Monopolistic benchmark}

In this section, we consider the case where both products are offered by the same (monopolistic) supplier. Due to symmetry a monopolist will choose identical price schedules for both products and we can restrict our attention to one side of the Hotelling line. If the monopolist commits to a decreasing price schedule then all consumers would prefer

\footnotetext{
${ }^{9}$ For example, $41 \%$ of all routes in Borenstein and Rose's (1994) study of the 1986 US industry are served by either one or two carriers. In Gerardi and Shapiro (2009) the average Herfindhal varies between 0.72 and 0.78 during 1993-2006.
} 
to purchase in period 2 rather than in period 1 . Hence we can assume without loss of generality, that the monopolist sets $p_{1} \leq p_{2}$. In the proof of Proposition 1, contained in the Appendix, we show that the monopolist will optimally sell to all consumers and offer a discount $\Delta p=p_{2}-p_{1}>0$ to those customers who purchase in advance. Here we offer a derivation of the optimal discount which makes the interpretation of the subsequent results more intuitive.

For this purpose, consider a consumer of type $x \in\left[0, \frac{1}{2}\right]$. The consumer obtains utility $U_{1, A}(x)=s-p_{1}-\gamma t x-(1-\gamma) t(1-x)$ from buying product $A$ in period 1 . If he waits until period 2, he will purchase product $A$ when located at $\hat{x}=x$ and product $B$ when located at $\hat{x}=1-x$. His expected utility from waiting is therefore given by $V_{A B}(x)=s-p_{2}-t x$. The difference

$$
V_{A B}(x)-U_{1, A}(x)=t(1-\gamma)(1-2 x)-\Delta p=t(1-\gamma) \sigma-\Delta p
$$

can be interpreted as the consumer's value of waiting. It is strictly decreasing in $x$ (consumers with a higher preference intensity $\sigma$ have a greater value of waiting) and becomes zero at

$$
x_{W}=\frac{1}{2}-\frac{\Delta p}{2 t(1-\gamma)}<\frac{1}{2}
$$

Given a discount of size $\Delta p \in(0, t(1-\gamma))$, consumers in $\left[0, x_{W}\right)$ prefer to wait until period 2 whereas consumers in $\left(x_{W}, \frac{1}{2}\right]$ prefer to purchase early.

The monopolist's optimal selling strategy maximizes total surplus minus the sum of information rents. For a late buyer, surplus is given by $s-t x$. He obtains information rents $t\left(x_{W}-x\right)$ from pooling with consumers of type $x_{W}$. The monopolist is therefore able to extract a rent $s-t x_{W}$ from each type of consumer in $\left[0, x_{W}\right]$. Similarly, for an early buyer surplus is $s-\gamma t x-(1-\gamma) t(1-x)$ and information rents are $t\left[\frac{1}{2}-\gamma x-(1-\gamma)(1-x)\right]$. The monopolist can extract the rent $s-\frac{t}{2}$ from each type of consumer in $\left(x_{W}, \frac{1}{2}\right]$. Due to (2), the choice of a discount $\Delta p$ is equivalent to the selection of a cutoff $x_{W}$. A high cutoff is good for total surplus due to the elimination of the potential product mismatch for early buyers. However, a high cutoff also leads to high information rents since it enables late buyers to pool with consumers characterized by relatively high transportation costs. The optimal $x_{W}$ trades off the surplus gains from the elimination of potential mismatch with the losses in information rents. Formally,

$$
x_{W}^{M}=\arg \max _{x_{W} \in\left(0, \frac{1}{2}\right)} x_{W}\left(s-t x_{W}\right)+\left(\frac{1}{2}-x_{W}\right)\left(s-\frac{t}{2}\right)=\frac{1}{4}
$$


and (2) leads the monopolist's optimal discount $\Delta p^{M}=\frac{t}{2}(1-\gamma)$. Finally, the price level is determined to make the consumer with the highest transportation cost $x=\frac{1}{2}$ indifferent between buying and not buying, leading to $p_{1}^{M}=s-\frac{1}{2} t$. In summary, we have:

Proposition 1 The profit maximizing monopolistic price schedule $\left(p_{1}^{M}, p_{2}^{M}\right)$ is given by $p_{1}^{M}=s-\frac{t}{2}$ and $p_{2}^{M}=s-\gamma \frac{t}{2}$. It offers an APD of size $\Delta p^{M}=p_{2}^{M}-p_{1}^{M}=\frac{t}{2}(1-\gamma)>0$ which induces a fraction $\sigma^{M}=\frac{1}{2}$ of consumers to buy in advance.

The following comparative statics results are immediate:

Corollary 1 In markets with a higher level of individual demand uncertainty (lower $\gamma$ ) a monopolist will offer a larger APD and earn greater profits.

To understand the intuition for this result, consider the effect of a decrease in $\gamma$. Since the first period price is set to extract the entire surplus from the buyers who are indifferent between both products, it is independent of $\gamma$. As consumers become more uncertain about their individual preferences, they are willing to pay a larger premium for a late purchase. Since, independently of $\gamma$, half of the consumers are induced to purchase late, the monopolist's profits increase. As can be seen from (1), a higher level of demand uncertainty (lower $\gamma$ ) makes consumers more heterogeneous with respect to their preferred timing of purchase. This facilitates intertemporal price discrimination, leading to higher profits for the monopolist.

\section{Competition}

In order to understand the effect of competition on intertemporal price discrimination suppose for the remainder that products $A$ and $B$ are offered by two competing firms. Each firm $i \in\{A, B\}$ chooses a price schedule $\left(p_{1, i}, p_{2, i}\right) \in \Re_{+}^{2}$. Without loss of generality, we can restrict the firms' strategy space by requiring $p_{1, i} \leq p_{2, i}$. This is because if firm $i$ chooses a decreasing price schedule, then its first period demand is zero and the firm can obtain the same profit by raising $p_{1, i}$ until it becomes equal to $p_{2, i}$.

Given the symmetry of the setup, we focus on a symmetric equilibrium in which firms offer the same price schedule, denoted as $\left(p_{1}^{*}, p_{2}^{*}\right)$. We will say that firms practice (intertemporal) price discrimination when they offer an APD, $p_{1}^{*}<p_{2}^{*}$, and sell to a positive number of consumers in both periods. Below we derive necessary conditions for an equilibrium in which firms practice price discrimination. For this purpose, we assume that firm $B$ chooses the equilibrium price schedule and consider a small deviation by firm $A$. This allows us to determine the unique candidate $\left(p_{1}^{*}, p_{2}^{*}\right)$ for such an equilibrium. In 
the proof of Proposition 2, contained in the Appendix, we show that $\left(p_{1}^{*}, p_{2}^{*}\right)$ is indeed an equilibrium by verifying the non-profitability of all possible deviations. There we also show that uniform pricing, $p_{1}=p_{2}$, cannot be an equilibrium. When prices are identical across periods, all consumers buy in period 2 , giving firms an incentive to attract additional (first period) demand through the implementation of an APD. ${ }^{10}$

In order to derive profits as a function of prices, it is necessary to understand the consumers' behavior. If a consumer of type $x \in[0,1]$ buys in period 1 , his expected payoff is $U_{1, A}(x) \equiv s-p_{1}-\gamma t x-(1-\gamma) t(1-x)$ if he buys from firm $A$ and $U_{1, B}(x) \equiv$ $s-p_{1}^{*}-\gamma t(1-x)-(1-\gamma) t x$ if he buys from firm $B$. The consumer prefers $A$ over $B$ in period 1 if and only if

$$
U_{1, A}(x)>U_{1, B}(x) \Leftrightarrow x<\frac{1}{2}-\frac{p_{1}-p_{1}^{*}}{2 t(2 \gamma-1)} \equiv x_{A B} .
$$

Similarly, in period 2, a consumer who turns out to be located at $\hat{x} \in[0,1]$ obtains the payoff $U_{2, A}(\hat{x}) \equiv s-p_{2}-t \hat{x}$ if he purchases product $A$ and $U_{2, B}(\hat{x}) \equiv s-p_{2}^{*}-t(1-\hat{x})$ if he purchases product $B$. The consumer prefers $A$ over $B$ in period 2 if and only if

$$
U_{2, A}(\hat{x})>U_{2, B}(\hat{x}) \Leftrightarrow \hat{x}<\frac{1}{2}-\frac{p_{2}-p_{2}^{*}}{2 t} \equiv \hat{x}_{A B}
$$

A consumer will postpone his purchase only if his product choice in period 2 depends on his realized location. If in period 2 , the consumer were to buy the same product independently of his realized location, he would be better off buying it already in period 1 at a lower price. In particular, if $\hat{x}_{A B}<\frac{1}{2}$ then all consumers with types $x \in\left(\hat{x}_{A B}, 1-\hat{x}_{A B}\right)$ would prefer $B$ over $A$ in period 2 no matter whether they turn out to be located at $\hat{x}=x$ or at $\hat{x}=1-x$. Similarly, if $\hat{x}_{A B}>\frac{1}{2}$ then all consumers with types $x \in\left(1-\hat{x}_{A B}, \hat{x}_{A B}\right)$ would prefer $A$ over $B$ in period 2 independently of their realized location. Hence consumers with types $x \in\left[\min \left(\hat{x}_{A B}, 1-\hat{x}_{A B}\right), \max \left(\hat{x}_{A B}, 1-\hat{x}_{A B}\right)\right]$ will never postpone their purchase.

A consumer with type $x<\min \left(\hat{x}_{A B}, 1-\hat{x}_{A B}\right)$ who waits until period 2 will purchase product $A$ when located at $\hat{x}=x$ and product $B$ when located at $\hat{x}=1-x$. His expected payoff from postponing his purchase is thus given by $V_{A B}(x) \equiv s-\gamma p_{2}-(1-\gamma) p_{2}^{*}-t x$. He prefers waiting over buying $A$ in period 1 if and only if

$$
V_{A B}(x)>U_{1, A}(x) \Leftrightarrow x<x_{A W} \equiv \frac{1}{2}-\frac{(1-\gamma) p_{2}^{*}+\gamma p_{2}-p_{1}}{2 t(1-\gamma)} .
$$

\footnotetext{
${ }^{10}$ Although this shows that in any equilibrium, firms will offer an APD, it does not necessarily imply that firms practice price discrimination. To see this, suppose that both firms set a very high second period price. Then no consumer will ever purchase from firm $B$ in the second period independently of the pricing of firm $A$. Knowing this, consumers derive no value from waiting until their uncertainty has been resolved. Hence all sales take place in the first period and, similar to the Hotelling model, the equilibrium price is readily determined: $p_{1}=t(2 \gamma-1)$. Although firms offer an APD, all units are sold at the same (uniform) price in period 1.
} 
Similarly, a consumer with type $x>\max \left(\hat{x}_{A B}, 1-\hat{x}_{A B}\right)$ will purchase $B$ in period 2 when located at $\hat{x}=x$ and product $A$ when located at $\hat{x}=1-x$. His expected payoff from waiting is $V_{B A}(x) \equiv s-\gamma p_{2}^{*}-(1-\gamma) p_{2}-t(1-x)$. He prefers waiting over buying $B$ in period 1 if and only if

$$
V_{B A}>U_{1, B}(x) \Leftrightarrow x>x_{B W} \equiv \frac{1}{2}+\frac{\gamma p_{2}^{*}+(1-\gamma) p_{2}-p_{1}^{*}}{2 t(1-\gamma)}
$$

If the first price deviation $\left|p_{1}-p_{1}^{*}\right|$ is relatively small compared to the second price deviation $\left|p_{2}-p_{2}^{*}\right|$ then it holds that $\min \left(\hat{x}_{A B}, 1-\hat{x}_{A B}\right)<x_{A B}<\max \left(\hat{x}_{A B}, 1-\hat{x}_{A B}\right)$. In this case the comparisons in (6) and (7) are indeed the relevant ones. ${ }^{11}$ Moreover, for small deviations it holds that $x_{A B} \approx \frac{1}{2}$ and $p_{1}^{*}<p_{2}^{*}$ implies that $x_{A W}<x_{A B}<x_{B W}$, i.e. both firms have positive demand in period 1 . For demands to be positive also in period 2 we postulate (and verify below) that in equilibrium $x_{A W}>0$ and $x_{B W}<1$. Firm $A$ 's profit is then given by

$$
\Pi_{A}=p_{1}\left(x_{A B}-x_{A W}\right)+p_{2}\left[\gamma x_{A W}+(1-\gamma)\left(1-x_{B W}\right)\right] .
$$

Note that firm $A$ 's second period demand consists of two parts: consumers with type $x<x_{A W}$ who wait and turn out to be located at $\hat{x}=x$; and consumers with type $x>x_{B W}$ who wait and turn out to be located at $\hat{x}=1-x$.

If an equilibrium exists, then at $\left(p_{1}, p_{2}\right)=\left(p_{1}^{*}, p_{2}^{*}\right)$ it has to hold that $\frac{\partial \Pi_{A}}{\partial p_{1}}=\frac{\partial \Pi_{A}}{\partial p_{2}}=0$. This leads the following two necessary conditions for an equilibrium

$$
\begin{aligned}
\frac{p_{2}^{*}-p_{1}^{*}}{2 t(1-\gamma)}-p_{1}^{*}\left(\frac{1}{2 t(1-\gamma)}+\frac{1}{2 t(2 \gamma-1)}\right)+p_{2}^{*} \gamma \frac{1}{2 t(1-\gamma)}=0 \\
p_{1}^{*} \frac{\gamma}{2 t(1-\gamma)}+\frac{1}{2}-\frac{p_{2}^{*}-p_{1}^{*}}{2 t(1-\gamma)}-p_{2}^{*}\left[\gamma \frac{\gamma}{2 t(1-\gamma)}+(1-\gamma) \frac{1}{2 t}\right]=0 .
\end{aligned}
$$

The unique solution to this system of equations is given by

$$
\begin{aligned}
& p_{1}^{*}=\frac{2(1+\gamma)\left(\gamma-\frac{1}{2}\right)}{-4 \gamma^{2}+7 \gamma-1} t \in(0, t) \\
& p_{2}^{*}=\frac{3 \gamma-1}{-4 \gamma^{2}+7 \gamma-1} t \in\left(p_{1}^{*}, t\right)
\end{aligned}
$$

It is easy to verify that at $\left(p_{1}, p_{2}\right)=\left(p_{1}^{*}, p_{2}^{*}\right)$ it holds that $x_{A W}>0 \Leftrightarrow x_{B W}<1 \Leftrightarrow$ $\Delta p^{*} \equiv p_{2}^{*}-p_{1}^{*}<t(1-\gamma) \Leftrightarrow 0<(1-\gamma)(4 \gamma-1)$. Since the last inequality holds for

\footnotetext{
${ }^{11}$ For other deviations $x_{A B}<\min \left(\hat{x}_{A B}, 1-\hat{x}_{A B}\right)$ or $x_{A B}>\max \left(\hat{x}_{A B}, 1-\hat{x}_{A B}\right)$. This complicates the analysis necessary to rule out the existence of a profitable deviation. For details see the proof of Proposition 2 contained in the Appendix.
} 
all $\gamma \in\left(\frac{1}{2}, 1\right)$ our assumption that $x_{A W}>0$ and $x_{B W}<1$ was therefore satisfied. Also note that our derivation implicitly assumed that all consumers buy in some period at the prices established in equilibrium. For this to happen, the consumer with the lowest valuation $x=\frac{1}{2}$ must obtain non-negative utility, i.e. $s-\frac{t}{2}-p_{1}^{*} \geq 0$ which is equivalent to Assumption 1 being satisfied. In summary we thus have:

Proposition 2 In a symmetric equilibrium firms offer APDs. There exists a unique symmetric equilibrium in which firms practice price discrimination: Firms choose the price schedule $\left(p_{1}^{*}, p_{2}^{*}\right)$ given by (11) and (12) and serve a fraction $\sigma^{*}=2 \gamma\left[-4 \gamma^{2}+7 \gamma-1\right]^{-1} \in$ $\left(\frac{2}{3}, 1\right)$ of their customers in advance.

The following comparative statics results are proved in the Appendix:

Corollary 2 In markets with a higher level of individual demand uncertainty (lower $\gamma$ ) competing firms will charge lower prices and offer larger APDs. Firms will serve a smaller fraction of their customers in advance and earn smaller profits.

A higher level of uncertainty (smaller $\gamma$ ) makes consumers less willing to buy in advance. As a response, firms will offer a larger APD. However, the discount chosen in equilibrium is not sufficient to offset the consumers' reduced willingness to buy in advance. As a consequence, the number of units sold in advance goes down. This stands in sharp contrast to the monopoly case in which the number of units sold in advance is independent of $\gamma$.

The fact that profits are increasing in $\gamma$ also contrasts with the decreasing profits under monopoly. This can be explained as follows. A decrease in $\gamma$ makes consumers more heterogeneous with respect to their propensity to wait in (1), making intertemporal price discrimination more profitable. However, in the presence of competition, a decrease in $\gamma$ has a second effect. It makes the two products appear more homogeneous from the consumers' viewpoint in period 1 . The less certain consumers are about the identity of their preferred product, the more indifferent they become between purchasing product $A$ or product $B$ in advance. As a consequence, advance competition becomes stronger, leading to a reduction in first period prices. Corollary 2 shows that the negative effect on advance competition is strong enough to offset the positive effect on the firms' ability to screen customers.

\section{$5 \quad$ Price and allocative effects}

We are now ready to compare the duopolistic outcome with the (multi-product) monopolistic benchmark in order to analyze the effects of competition in markets with individual 
demand uncertainty. In this section we focus on the effects on prices and the resulting intertemporal allocation of sales. Welfare effects are the subject of the following section.

Figure 1 depicts the intertemporal allocation of sales for the two market structures. From Proposition 1 we know that a monopolist divides the market into two segments of

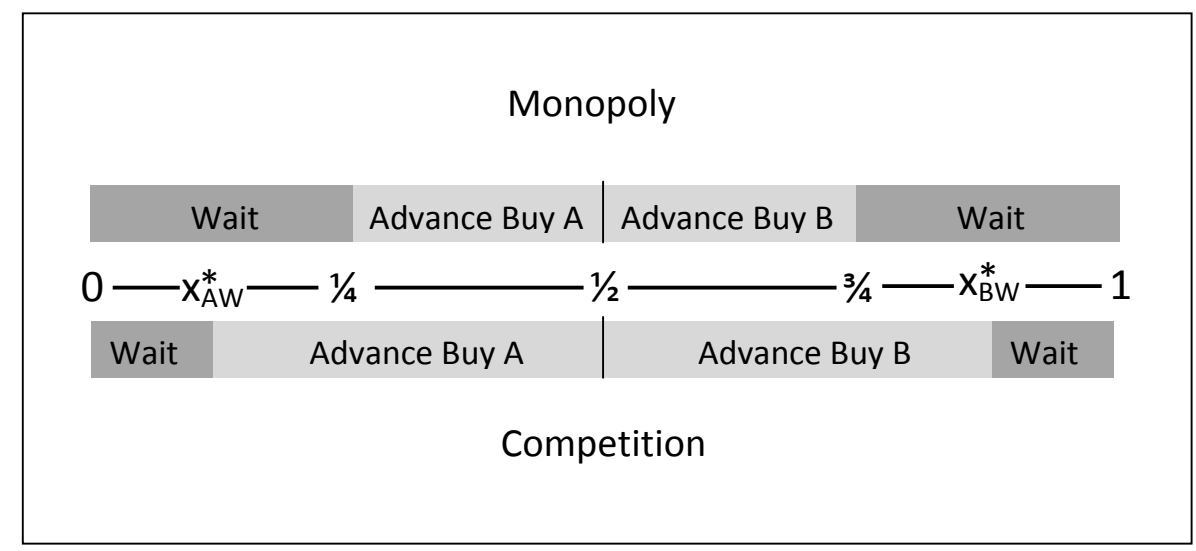

Figure 1: Intertemporal allocation of sales: Comparison monopoly versus competition.

equal size. Under competition, the thresholds $x_{A W}^{*}$ and $x_{B W}^{*}$ are readily determined from Proposition 2: $x_{A W}^{*}=\frac{1}{2}\left(1-\sigma^{*}\right)<\frac{1}{4}$ and $x_{B W}^{*}=1-x_{A W}^{*}=\frac{1}{2}\left(1+\sigma^{*}\right)>\frac{3}{4}$. There exists a group of consumers with intermediate preference intensities who would postpone their purchase under monopoly but are induced to buy in advance under competition. In other words, under competition the majority of the consumers buy at a discount leading to a less pronounced segmentation of the market. This gives:

Proposition 3 Competing firms offer larger advance purchase discounts than a monopolist, both in absolute $\left(\Delta p^{*}>\Delta p^{M}\right)$ and relative $\left(\frac{\Delta p^{*}}{p_{1}^{*}}>\frac{\Delta p^{M}}{p_{1}^{M}}\right)$ terms. Competition leads to lower market segmentation due to an increase in the fraction of consumers served in advance $\sigma^{*}>\sigma^{M}$.

To understand the intuition for this result, recall that a monopolist benefits from lowering his APD due to the elimination of a potential mismatch for those consumers who switch from buying in advance to waiting. In the presence of competition, firms fail to internalize fully the corresponding increase in consumer surplus. This is because only a fraction $\gamma$ of the consumers who are induced to postpone their purchase by the ADP of firm $A$, will eventually become customers of this firm. The remaining fraction $1-\gamma$ will purchase from firm $B$ and the increment in these consumers' surplus will be extracted by firm $A$ 's rival. Under competition firms induce less consumers to postpone their purchase 
than under monopoly since they fail to internalize the positive externality of an improved consumer-product matching on the rival firm.

In order to relate to the empirical controversy about the effect of competition on price dispersion, we now compare the Gini coefficients under monopoly and under competition. For a given price distribution, the Gini coefficient is defined as (one half of) the expected absolute price difference between two prices drawn at random, divided by the average price. Given a fraction $\sigma \in(0,1)$ of consumers who buy at $p_{1}$ and a fraction $1-\sigma$ who buy at $p_{2}$, the Gini coefficient is therefore given by

$$
G=\frac{\Delta p}{\bar{p}} \cdot \sigma(1-\sigma)
$$

where we have introduced $\bar{p} \equiv \sigma p_{1}+(1-\sigma) p_{2}$ to denote the average price. In the Appendix we prove the following:

Proposition 4 Competition decreases price dispersion if product differentiation is high but increases price dispersion if product differentiation is low: $G^{*}>G^{M} \Leftrightarrow t<t^{\text {Gini }}(\gamma)$. The threshold $t^{\text {Gini }}(\gamma)$ is decreasing in $\gamma \in\left(\frac{1}{2}, 1\right)$ with $\lim _{\gamma \rightarrow 1} t^{\text {Gini }}=0$.

The threshold $t^{\text {Gini }}(\gamma)$ can be determined in closed form (see Appendix) and is depicted in Figure 2. To understand this result, note from (13) that price dispersion depends on two factors; the size of the price range $\Delta p$ normalized by the average price $\bar{p}$; and the degree of market segmentation as expressed by the term $\sigma(1-\sigma)$. It thus follows from Proposition 3 that competition affects price dispersion via two opposed channels. Since discounts are larger under competition and the average price level is necessarily higher under monopoly, competition has a positive effect on the normalized price range, $\frac{\Delta p^{*}}{\bar{p}^{*}}-\frac{\Delta p^{M}}{\bar{p}^{M}}>0$. On the other hand, the effect of competition on market segmentation is negative, $\sigma^{*}\left(1-\sigma^{*}\right)-\sigma^{M}\left(1-\sigma^{M}\right)<0$.

While the segmentation effect is independent of the degree of product differentiation, the price effect is diminishing in $t$. This is driven by the fact that monopolistic rent extraction makes the average price $\bar{p}^{M}=s-\frac{(1+\gamma) t}{4}$ decrease in $t$ while under competition all prices increase (proportionally) as products become more differentiated. ${ }^{12}$ Hence as $t$ increases, the negative segmentation effect becomes able to outweigh the positive, but diminishing, price effect. The threshold $t^{\text {Gini }}$ is increasing in the level of demand uncertainty since, as shown in Corollary 2, for lower values of $\gamma$ the effect of competition on market segmentation becomes less pronounced.

\footnotetext{
${ }^{12}$ For the same reason $G^{*}$ is independent of $t$. This is an artifact of our assumption that marginal costs are zero. For positive marginal costs, $G^{*}$ and $G^{M}$ are both increasing in $t$ and tend to zero for $t \rightarrow 0$. For details see the robustness section below.
} 


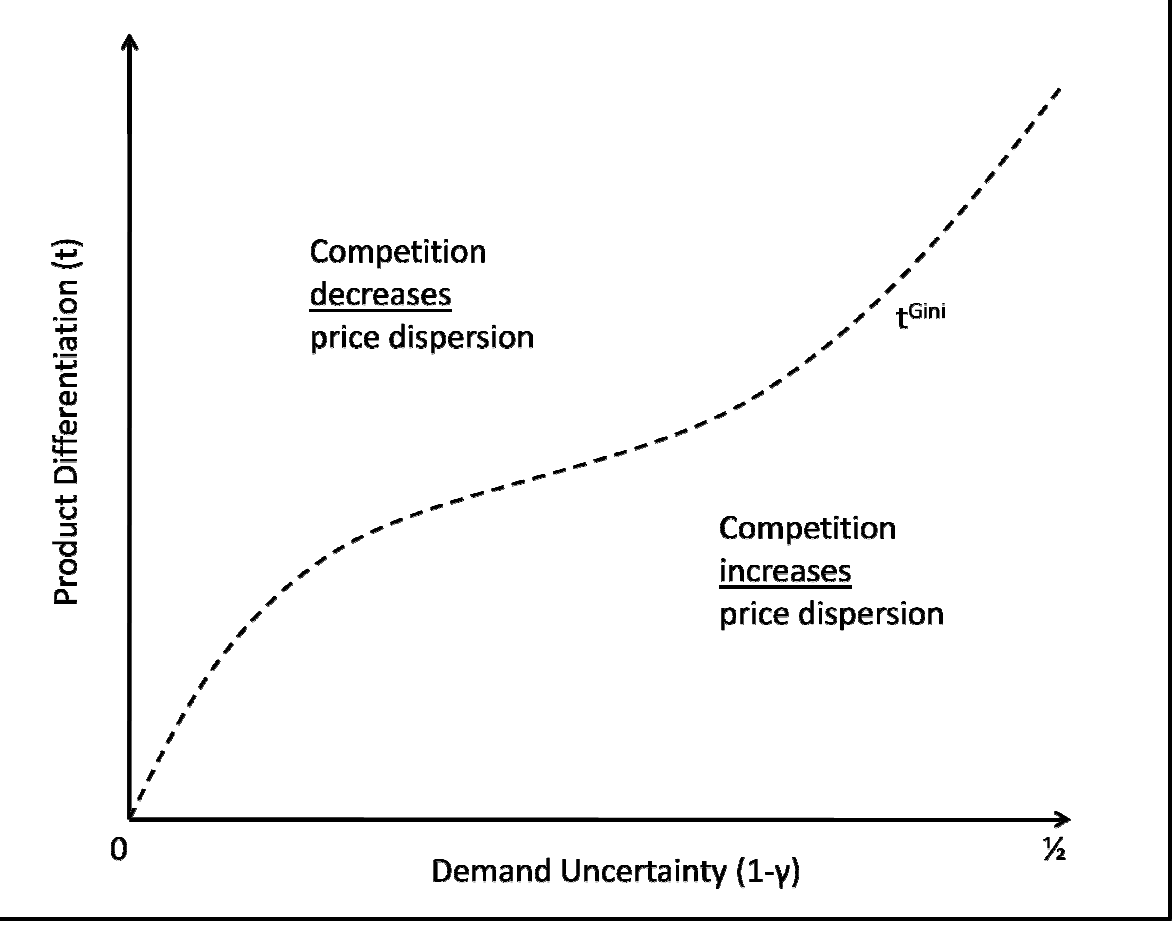

Figure 2: The Effect of Competition on Price Dispersion: The dashed line $\left(t^{\text {Gini }}\right)$ separates the areas of the parameter space in which competition increases $\left(G^{*}>G^{M}\right)$ or decreases $\left(G^{*}<G^{M}\right)$ price dispersion.

Note that in a market characterized by a higher degree of product differentiation and a lower level of demand uncertainty consumers are more heterogeneous with respect to their (ex ante) preferences. Hence Proposition 4 is consistent with Gerardi and Shapiro's (2009) empirical finding that the negative effect of competition on price dispersion is more pronounced for airline routes with a more heterogeneous customer base.

Finally, with respect to the welfare analysis contained in the following section it is important to consider the effect of competition on advance prices and spot prices in separation. In the Appendix we prove the following:

Proposition 5 Competition reduces the price payed by early buyers, $p_{1}^{*}<p_{1}^{M}$. Whether competition increases or decreases the price payed by late buyers depends on the degree of product differentiation: $p_{2}^{*}>(<) p_{2}^{M}$ if $t>(<) t^{\text {Spot }}(\gamma)$. The threshold $t^{\text {Spot }}(\gamma)$ is decreasing in $\gamma \in\left(\frac{1}{2}, 1\right)$.

At first sight, it seems surprising that competition may lead to an increase in (spot) prices. However, there exists empirical evidence showing exactly this. Borenstein's (1989) finds that more competitive airline routes are characterized by lower 20th percentile fares but 
higher 80th percentile fares. Proposition 5 provides an explanation for this finding. It predicts, that the effect should be particularly strong for routes with a high degree of product differentiation.

To understand why competition may lead to an increase in spot prices, note that competing firms, having served a larger number of customers in advance, face a spot market consisting of a more select group of consumers with strong preferences. Within this group, "convenience of schedule" is of utmost importance, allowing firms to charge a higher price when the competitive pressure on prices is sufficiently weak, that is, when products are sufficiently differentiated. Spot prices can be higher under competition since by selling to a larger group of consumers with low preference intensities in advance, firms have increased their market power with respect to the remaining customers. The threshold $t^{\text {Spot }}(\gamma)$ is decreasing in $\gamma$ since, by Corollary 2, the fraction of consumers who are served in advance under competition is larger for lower levels of demand uncertainty.

\section{Relation to non-linear pricing}

Our model allows the following interpretation. Suppose that in period 1 each firm $i \in$ $\{A, B\}$ offers a non-refundable product at price $p_{1, i}$ and a refundable product at price $p_{2, i}$. In period 2 , consumers who purchased a refundable product from firm $i$ may return it in exchange for its full price $p_{2, i}$ and purchase a new product from firm $j \neq i$ at price $p_{2, j}$. Denote the refundable option as a high quality product $(q=1)$ and the non-refundable option as a low quality product $(q=0)$. Then, assuming for the moment that $p_{2, A}=p_{2, B}$, we can write a consumer's utility (net of payment) from purchasing quality level $q \in\{0,1\}$ of his ex ante preferred product as

$$
u(q, \sigma, \gamma)=s-\frac{t}{2}(1-\sigma)-(1-q)(1-\gamma) t \sigma .
$$

The first two terms represent the consumers utility from consuming his preferred brand. The last term is the (expected) disutility from consuming the wrong product when choosing the non-refundable option. In analogy to the non-linear pricing literature, $u(q, \sigma, \gamma)$ depends on a horizontal preference parameter, given by the consumer's brand preference intensity, $\sigma$, and a vertical preference parameter, in form of the consumer's demand uncertainty, $\gamma$. The determination of equilibrium price-quality menus for the general case of multi-dimensional consumer heterogeneity has proved difficult. In order to obtain analytical results, the literature has either considered the cases of horizontal and vertical heterogeneity in separation (Stole, 1995) or made the simplifying assumption that the consumer's marginal valuation of quality is independent of his horizontal preference parameter (Armstrong and Vickers (2001), Rochet and Stole (2002)). As can be seen from 
(14), in our setting this assumption is not satisfied. Consumers with high $\sigma$ derive a higher value from a refundable ticket than consumers with low $\sigma$. Moreover, since $\gamma$ is the same for all consumers, unobserved preference heterogeneity is restricted to the horizontal dimension, making our setting most comparable to Stole (1995).

For the case of horizontal heterogeneity, Stole finds the surprising result that competing firms will implement the same quality distortions as a (multi-product) monopolist. Competition has the mere effect of decreasing prices and since incentive compatibility requires all prices to decrease by the same amount, price dispersion remains unaffected. In our setting, with its two exogenously given "quality" levels, this result is no longer valid. Competition enlarges the set of consumer types who are offered the low quality (non-refundable) option and incentive compatibility thus requires the price of low quality to decrease by a larger amount then the price of high quality.

Note, however, that the above comparison has its limitations. In particular, in our interpretation of refundability as quality we required the prices of the refundable products to be identical. When $p_{2, A} \neq p_{2, B}$ then such an interpretation is not possible, since a consumer's valuation of refundability fails to be independent of prices. For example, when $p_{2, B}$ is much higher than $p_{2, A}$, then the refundability of product $A$ has no value since no consumer will ever be willing to pay the price difference $p_{2, B}-p_{2, A}$ in order to eliminate a potential mismatch. Since in our model, $p_{2, A}=p_{2, B}$ holds in equilibrium but not off equilibrium, the comparison with non-linear pricing offered above has to be taken with caution.

\section{Robustness}

In the remainder of this section we consider the robustness of our results with respect to changes in our key assumptions. We first introduce a positive marginal cost of production and show that an increase in this cost makes competition become less likely to have a positive effect on price discrimination. The presence of a (sufficiently high) marginal cost allows us to drop our assumption about the non-feasibility of multiple purchases. We also consider the possibility of quadratic rather than linear transportation costs and extend our model to the case of $N \geq 2$ of firms/brands. An increase in the number of brands turns out to have no effect on price dispersion under competition but leads to a decrease in price dispersion under monopoly. 


\section{Positive marginal costs}

The main purpose of our assumption of zero marginal costs , $c=0$, was to simplify the proof of existence of a price discrimination equilibrium (Proposition 2). This proof is complicated by the presence of kinks in the firms' profit functions. Although a well known issue in models of horizontal product differentiation, in our setting the problem is exacerbated due to its temporal dimension. However, generalizing the necessary conditions for such an equilibrium (the equivalents of (9) and (10)) to the case where $c>0$ is an easy task. It is straight forward to show that a potential equilibrium must satisfy $p_{1}^{*}(c)=c+p_{1}^{*}(0)$ and $p_{2}^{*}(c)=c+p_{2}^{*}(0)$.

An immediate consequence of this finding is that under competition, advance purchase discounts and hence market segmentation are independent of $c$. Moreover, if parameters satisfy the generalized covered market assumption $s>c+\frac{9 \gamma-3}{-8 \gamma^{2}+14 \gamma-2}$, then monopoly pricing is entirely unaffected by the introduction of a positive marginal cost of production. With respect to the Gini coefficients, the only effect is an increase in the average price $\bar{p}^{*}$ under competition, leading to a reduction in $G^{*}$. This reduction is stronger for lower values of $t$. Hence Propositions 3 and 4 remain valid with the generalized threshold $t^{\text {Gini }}(c)$ being decreasing in $c$. In other words, an increase in the marginal cost of production, makes competition less likely to have a positive effect on the firms' ability to price discriminate.

\section{Multiple purchases}

In our model, waiting until period 2 constitutes the only means by which a consumer is able to rule out a potential mismatch. When multiple purchases are feasible two alternative possibilities exist. First, a consumer can insure himself against a mistmatch by buying both products in period 1. Second, a consumer can correct his purchase from period 1 by acquiring the correct product in period 2. It is intuitive that waiting dominates these multiple-purchase alternatives if prices are sufficiently high. In the previous section we have shown that equilibrium prices consist of a simple mark-up over marginal costs, i.e. $p_{1}^{*}(c)=c+p_{1}^{*}(0)$ and $p_{2}^{*}(c)=c+p_{2}^{*}(0)$. This means that when marginal costs are sufficiently high, our assumption about the non-feasibility of multiple purchases is no longer required.

To be specific, multiple purchases are dominated by waiting if $2 p_{1}^{*}(c)>p_{2}^{*}(c)$ and $p_{1}^{*}(c)+(1-\gamma) p_{2}^{*}(c)>p_{2}^{*}(c)$. It is easy to see that the second inequality constitutes the binding constraint and that it is equivalent to $p_{1}^{*}(c)>\gamma p_{2}^{*}(c)$ or $c>\frac{\gamma p_{2}^{*}(0)-p_{1}^{*}(0)}{1-\gamma}$. Since the right hand side is decreasing in $\gamma$, this inequality holds for all $\gamma \in\left(\frac{1}{2}, 1\right)$ if it holds for $\gamma \rightarrow \frac{1}{2}$, in which case it becomes $c>\frac{t}{3}$. Hence when marginal costs are sufficiently 
positive, multiple purchases are sub-optimal in equilibrium.

\section{Quadratic transportation costs}

One might be concerned that our finding, that competition reduces market segmentation, is driven by the fact that, under monopoly, market segmentation is maximal, which is due to our assumption that transportation costs are linear. Indeed, when transportation costs are assumed to be quadratic, monopolistic segmentation turns out to be less extreme. The monopolist will charge the prices $p_{1}^{M}=s-\frac{t}{4}$ and $p_{2}^{M}=p_{1}^{M}+\Delta p^{M}$ with the discount $\Delta p^{M}=t(1-\gamma)\left(1-\frac{1}{\sqrt{3}}\right)$ implying $\sigma^{M}=\frac{1}{\sqrt{3}}>\frac{1}{2}$.

Under competition, the change from linear to quadratic transportation costs has no influence on the demand thresholds $x_{A B}, x_{A W}$, and $x_{B W}$. Hence the equilibrium prices remain unchanged. The only effect is that Assumption 1 has to be modified to $s>$ $\frac{4 \gamma^{2}+11 \gamma-5}{4\left(-4 \gamma^{2}+7 \gamma-1\right)} t$. It is easy to confirm that Proposition 3 remains valid for the new monopoly prices and to prove Propositions 4 and 5 with appropriately adjusted thresholds $t^{\text {Gini }}$ and $t^{\text {Spot }}$. Hence our results are robust to a change from linear to quadratic transportation costs.

In a market with a large and a small segment, information rents are high due to the pooling of consumers with a high degree of preference heterogeneity. This explains the monopolist's incentive to partition the market into two segments of similar size. This incentive persists, independently of the particular shape of consumer preferences.

\section{More than two firms}

We can extend our model to a circular city framework by assuming that $N>2$ (identical) firms are located equidistantly along a circle with perimeter 1 , dividing the market into $N$ intervals of size $\frac{1}{N}$. In contrast to a setting with only two brands, there are now many possibilities how to model the consumers' demand uncertainty. Here we choose to stay as close as possible to our basic model by assuming that consumers know in which interval of the circle they are located but face uncertainty with respect to their preferences over the two brands at the interval's boundary. Formally, for any $M \in\{1,2, \ldots, N\}$, a consumer in the interval $\left[\frac{M-1}{N}, \frac{M}{N}\right]$ with preference intensity $\sigma \in[0,1]$ knows that he is located either in $\hat{x}=\frac{M-1}{N}+\frac{1-\sigma}{2 N}$ or in $\hat{x}=\frac{M-1}{N}+\frac{1+\sigma}{2 N}$. As before he receives a signal about his true location with precision $\gamma \in\left(\frac{1}{2}, 1\right)$.

Unfortunately, for higher $N$ the proof of existence of a price discrimination equilibrium (Proposition 2) becomes exceedingly complicated due to the increase in the number of kinks in the firms' profit functions. However, the necessary conditions for such an equi- 
librium can be determined as before. The only change is that in the demand thresholds (4), (6), and (7), and in the equilibrium condition (10) the term $\frac{1}{2}$ is substituted by the term $\frac{1}{2 N}$. As a result we obtain

$$
\begin{aligned}
& p_{1}^{*}(N)=\frac{2(1+\gamma)\left(\gamma-\frac{1}{2}\right)}{-4 \gamma^{2}+7 \gamma-1} \frac{t}{N} \\
& p_{2}^{*}(N)=\frac{3 \gamma-1}{-4 \gamma^{2}+7 \gamma-1} \frac{t}{N} .
\end{aligned}
$$

The fraction of consumers who are served in advance is given by

$$
\sigma^{*}(N)=N \frac{p_{2}^{*}(N)-p_{1}^{*}(N)}{t(1-\gamma)}
$$

Since equilibrium prices are proportional to $\frac{1}{N}$, the Gini coefficient under competition, $G^{*}$, is independent of $N$ and takes the same value as in our model with only two firms.

If the $N$ brands are supplied by a monopolistic firm, prices are easily determined to be $p_{1}^{M}=s-\frac{t}{2 N}$ and $p_{2}^{M}=s-\gamma \frac{t}{2 N}$. As before, the monopolist will serve half of the consumers in advance, i.e. $\sigma^{M}(N)=\frac{1}{2}$. Given that $\Delta p^{M}=(1-\gamma) \frac{t}{2 N}$ is decreasing in $N$ and $\bar{p}^{M}=s-\frac{t}{4 N}(1+\gamma)$ is increasing, it follows that the Gini coefficient under monopoly, $G^{M}$, is decreasing in $N$.

Hence Propositions 3 and 4 remain valid with the generalized threshold $t^{\operatorname{Gini}}(N)$ being increasing in $N$. In other words, an increase in the number of brands makes competition more likely to have a positive effect on the firms' ability to price discriminate.

\section{$6 \quad$ Welfare effects}

The model's assumptions of unitary demands and covered markets allow us to highlight the welfare effects that originate from the uncertain nature of individual preferences. In particular, price changes affect the intertemporal allocation of sales but have no influence on the overall quantity supplied. The potential mismatch between consumer-preferences and product-characteristics constitutes the sole source of welfare loss and total welfare would be maximized if all consumers were served after their uncertainty has been resolved.

Nevertheless, Propositions 1 and 2 show that, independently of market structure, firms will induce a number of consumers to make an uninformed purchase. Moreover, there exists a group of consumers with intermediate preference intensities, $\sigma \in\left(\frac{1}{2}, \sigma^{*}\right)$, who make an informed purchase under monopoly but an uninformed purchase under competition. A fraction $(1-\gamma)$ of these consumers incur a disutility of size $t \sigma$ from 
purchasing the wrong product. Hence there exists an additional welfare loss which is due to competition. It is given by

$$
W^{*}-W^{M}=-(1-\gamma) t \int_{\frac{1}{2}}^{\sigma^{*}} \sigma d \sigma=-\frac{1}{2}(1-\gamma) t\left[\left(\sigma^{*}\right)^{2}-\frac{1}{4}\right]<0 .
$$

Proposition 6 In comparison with the monopolistic benchmark, competition leads to a welfare loss: $W^{*}-W^{M}<0$. The (absolute) size of this welfare loss is increasing in the level of individual demand uncertainty.

So if competition leads to a welfare loss, to what extent are consumers affected? To answer this question, we consider how the change in a consumer's surplus depends on his preference intensity $\sigma \in[0,1]$ :

$$
C S^{*}(\sigma)-C S^{M}(\sigma)=\left\{\begin{array}{rll}
p_{1}^{M}-p_{1}^{*} & \text { if } & \sigma \leq \frac{1}{2} \\
p_{2}^{M}-p_{1}^{*}-t(1-\gamma) \sigma & \text { if } & \frac{1}{2}<\sigma<\sigma^{*} \\
p_{2}^{M}-p_{2}^{*} & \text { if } & \sigma^{*} \leq \sigma
\end{array}\right.
$$

Consumers with low preference intensities, $\sigma \in\left[0, \frac{1}{2}\right]$, purchase in advance under both market structures and therefore benefit from the lower first period prices $p_{1}^{*}<p_{1}^{M}$ charged under competition. Consumers with intermediate preference intensities, $\sigma \in\left(\frac{1}{2}, \sigma^{*}\right)$, switch from buying late under monopoly to buying early under competition. Switching buyers experience an even greater price reduction, $p_{2}^{M}-p_{1}^{*}>p_{1}^{M}-p_{1}^{*}>0$, at the (expected) cost of a potential product-mismatch, $(1-\gamma) t \sigma$. Note that for $p_{2}^{M}>p_{2}^{*}$ all switching buyers benefit from competition since their preference for buying early implies that $p_{2}^{*}-p_{1}^{*}-(1-\gamma) t \sigma>0$. Finally, consumers with high preference intensity, $\sigma \in\left[\sigma^{*}, 1\right]$, postpone their purchase under both market structures. Whether they benefit from competition depends on the comparison of second period prices.

The influence of competition on aggregate consumer surplus is given by

$$
\Sigma C S^{*}-\Sigma C S^{M}=W^{*}-W^{M}+p_{2}^{M}-\frac{1}{2} \Delta p^{M}-\left(p_{2}^{*}-\sigma^{*} \Delta p^{*}\right) .
$$

It consists of two parts: the welfare loss due to increased consumer-product mismatch; and a price effect. Under monopoly, the spot selling price is given by $p_{2}^{M}$ and half of the consumers buy at a discount $\Delta p^{M}$. Under competition, the spot selling price is given by $p_{2}^{*}$ and a higher fraction $\sigma^{*}>\frac{1}{2}$ of the consumers buy at a larger discount $\Delta p^{*}>\Delta p^{M}$.

Proposition 5 has shown that, under competition, second period prices are lower than under monopoly if and only if the degree of product differentiation, $t$, is below the threshold $t^{\text {Spot }}$. It therefore follows from the above that for $t \leq t^{\text {Spot }}$ competition has a positive 
effect on the surplus of each single consumer and thus $\Sigma C S^{*}-\Sigma C S^{M}>0$. However, the change in aggregate consumer surplus, $\Sigma C S^{*}-\Sigma C S^{M}$, is decreasing in the degree of product differentiation because under competition, prices are increasing in $t$ whereas under monopoly, prices are decreasing. In the Appendix we show the following:

Proposition 7 The effect of competition on consumer surplus depends on the degree of product differentiation, $t$, as follows:

1. For $t \leq t^{\text {Spot }}$, competition increases each consumer's surplus. For $t>t^{\text {Spot }}$, competition increases surplus for consumers with low preference intensities, but decreases surplus for consumers with high preference intensities: $C S^{*}(\sigma)>(<) C S^{M}(\sigma)(t)$ if $\sigma<(>) \sigma^{C S}$. The threshold $\sigma^{C S}(t) \in\left(\frac{1}{2}, \sigma^{*}\right)$ is decreasing in $t$.

2. Competition increases (decreases) aggregate consumer surplus when the degree of product differentiation is low (high): $\Sigma C S^{*}>(<) \Sigma C S^{M}$ if $t<(>) t^{C S}(\gamma)$. The threshold $t^{C S}(\gamma)$ is decreasing in $\gamma$ and $t^{C S}(\gamma)>t^{S p o t}(\gamma)$ for all $\gamma \in\left(\frac{1}{2}, 1\right)$.

Since consumers are free to choose their timing of purchase, they will only buy in advance when the implied price discount more than compensates for the increased risk of a mismatch. This implies that when competition lowers prices in both periods, all consumers must be better off. For competition to have a negative effect on consumer surplus it must therefore lead to an increase in price(s). In Proposition 5 we have seen that competition may lead to an increase in price only in the second period and only when the degree of product differentiation is sufficiently high. This shows that the possibility of a decrease in aggregate consumer surplus is due to the higher prices payed by late buyers, i.e. by those with strong preference intensities (business travelers). Consumers with low preference intensities (leisure travelers) unambiguously benefit from the introduction of competition.

\section{$7 \quad$ Uniform pricing}

In this section we compare the setting in which intertemporal price discrimination is feasible with the case where ADPs are ruled out by the requirement of uniform pricing: $p_{1}=p_{2}=p$. When firms are not allowed to charge different prices across periods, a sale can occur only in period 2. Hence firms solve the standard Hotelling problem. The equilibrium price is given by $p^{*}=t$ and all buyers participate in the market if and only if $t<\frac{2}{3} s$. With these parameter values, all buyers participate under monopoly as well, where a monopolistic seller charges a price equal to $p^{M}=s-\frac{t}{2}>p^{*}$. 
In contrast to the case where APDs are allowed, competition has no influence on total welfare. Under both market structures, all consumers make an informed purchase and there is no mismatch between consumer preferences and product characteristics. Moreover, by decreasing the price, competition raises the surplus of all consumers independently of their preference intensity and the degree of product differentiation. This shows that our finding from the previous section, that competition can be detrimental both for total welfare as well as for consumer surplus, is driven by the firms' ability to practice intertemporal price discrimination.

So what is the effect of intertemporal price discrimination on consumer surplus? For a monopolistic market it is straight forward to see that any consumer's surplus is lower with APDs than without. This is because, under uniform pricing, a monopolist would offer a price, $p^{M}$, that is the same as the first period price, $p_{1}^{M}$, of an APD. In the presence of an $\mathrm{APD}$, those consumers who buy in period 1 therefore face the additional risk of obtaining the wrong product, while those who buy in period 2, pay a higher price.

Under competition, allowing for intertemporal price discrimination has the opposite effect. The possibility of intertemporal price discrimination leads to lower prices for both periods: $p_{1}^{*}<p^{*}$ and $p_{2}^{*}<p^{*}$. As a consequence, price discrimination leaves all consumers better off. We summarize these findings in the following:

Proposition 8 A ban on advance purchase discounts leads to an increase in welfare independently of market structure. It leads to an increase in consumer surplus and a decrease in profits under monopoly but has the opposite effect under competition.

The first part of Proposition 8 is in line with the general view that for price discrimination to have a positive effect on welfare it must lead to an increase in sold quantities (see Stole (2007) and references therein). Since in our setting, quantities are unaffected, the sole effect of price discrimination is the creation of consumer misallocations.

The second part of Proposition 8 is reminiscent of the findings of Thisse and Vives (1988), Corts (1998), Villas-Boas (1999) and Fudenberg and Tirole (2000) for the case of third-degree price discrimination. However, while in those models consumers are "related" in an observable way to a particular firm, in our setting consumer characteristics are unobservable. Proposition 8 extends the insight that competitive price discrimination may lead to a decreases of all prices to the case of intertemporal (second-degree) price discrimination. 


\section{Conclusion}

In this paper we have provided a tractable model of oligopolistic (intertemporal) price discrimination which allows us to study issues of high relevance for differentiated product markets. The model is based on the assumption that consumers learn their preferences over time and differ with respect to the importance they attach to obtaining their most preferred product. Firms offer advance purchase discounts in order to discriminate consumers with respect to the strength of their preferences. By doing so, firms exploit the consumers' trade-off between an (early) uninformed purchase at a low price and a (late) informed purchase at a high price.

We have focused on the influence of market structure on the firms' ability to price discriminate. Our main result shows that, while competition has a positive effect on price dispersion when demand uncertainty is high or product differentiation is low, the effect is negative when preferences are sufficiently certain and products are relatively differentiated. This result suggests further empirical investigation of airline pricing along the lines of Borenstein and Rose (1994) and Gerardi and Shapiro (2009). One may argue that on routes offering a Tuesday and a Thursday flight product differentiation is higher than on routes offering a Tuesday and a Wednesday flight. Alternatively, when fare discount rules are more stringent, in that tickets are required to be purchased a longer time in advance, the buyers' level of uncertainty is higher. Controlling for product differentiation and demand uncertainty may help to shed light on the empirical controversy about the relationship between competition and price discrimination. ${ }^{13}$

Although well suited for a variety of settings, our assumption of unitary demands implies that welfare predictions have to be taken with caution. Nevertheless, our model has highlighted the existence of a negative effect of competition on markets characterized by individual demand uncertainty. We have shown that competition leads to an increase in the number of uninformed purchases and hence to a greater amount of mismatch between consumer preferences and product characteristics. To the best of our knowledge this welfare loss of competition has not been pointed out in the literature.

From the consumers' point of view, the greater risk of misallocation may be compensated by lower prices. We have shown that competition leads to an increase in (aggregate) consumer surplus if and only if product differentiation is low. When products are suf-

\footnotetext{
${ }^{13} \mathrm{~A}$ first step into this direction has been taken by Moon and Watanabe (2013). Using an approach similar to Borenstein and Rose (1994), these authors include a route's refund premium, i.e. the average price difference between a refundable and a non-refundable ticket, as a control for the level of individual uncertainty. They show that the inclusion of the refund premium makes the coefficient on market concentration change its sign.
} 
ficiently differentiated, competition has a negative effect on consumer surplus since it increases the prices charged to late buyers. Our results also suggest that the introduction of competition should go hand in hand with a deregulation of pricing. In particular, we have shown that price regulation in form of a ban on advance purchase discounts is beneficial for consumers in a monopolistic market, but has a negative effect under competition.

It is worth pointing out that this link between competition policy and price regulation is not a mere theoretical construct. An example from a deregulation episode can be found in the Japanese airline industry. Until the mid 1990s Japanese domestic routes were regulated to be served monopolistically by one of the three existing airlines, Japan Airlines, All Nippon Airways, and Japan Air System. In 1990, the Ministry of Transport decided to allow a second carrier on routes with more than 700,000 passengers a year. The hurdle for "double tracking" was lowered further to 400,000 in 1992 and to 200,000 in 1994. In 1994, the ministry also announced that it would allow discounts on domestic fares of up to $50 \%$ for "strategic business reasons". This price deregulation granted companies the right to use advance purchase discounts and other forms of price discrimination. It set an end to the standard practice of ministry approved (uniform) cost-plus pricing. According to Alexander (2000), the average price payed per passenger-kilometer decreased from 22 Yen in 1990 to 17 Yen in 1998. This could be understood as evidence for the powerful combination of competition and price discrimination.

\section{Appendix - Proofs}

\section{Proof of Proposition 1}

The monopolist has two options. He can either set prices such that all consumers buy (in some period) or instead choose a price schedule under which some consumers do not buy at all. Since a consumer with type $x=\frac{1}{2}$ obtains the lowest (expected) utility from buying and always prefers to buy in advance the two cases are distinguished by whether $p_{1}$ is smaller or greater than $s-\frac{t}{2}$ respectively. If $p_{1} \leq s-\frac{t}{2}$ then all consumers buy in some period and profits are

$$
\pi=2\left(\frac{1}{2}-x_{W}\right) p_{1}+2 x_{W} p_{2}=p_{1} \frac{p_{2}-p_{1}}{t(1-\gamma)}+p_{2}\left(1-\frac{p_{2}-p_{1}}{t(1-\gamma)}\right)=p_{2}-\frac{\left(p_{2}-p_{1}\right)^{2}}{t(1-\gamma)} .
$$

Since profits are increasing in $p_{1}$ it is optimal to set $p_{1}=s-\frac{t}{2}$. Moreover with respect to $p_{2}$, profits are strictly concave in $\left[p_{1}, p_{1}+t(1-\gamma)\right]$ and

$$
\frac{\partial \pi}{\partial p_{2}}=1-\frac{2\left(p_{2}-p_{1}\right)}{t(1-\gamma)}=0 \Leftrightarrow p_{2}=p_{1}+\frac{1}{2} t(1-\gamma) .
$$


Note that this price implies an APD of size $\Delta p=\frac{1}{2} t(1-\gamma)$ and $x_{W}=\frac{1}{4}$. Hence we have shown that if the monopolist sells to all consumers then he will do so by way of an APD. It remains to show that the monopolist has no incentive to restrict his sales by charging a higher price $p_{1}>s-\frac{t}{2}$.

A consumer of type $x$ who prefers buying in advance over waiting will refrain from buying all together if and only if

$$
s-p_{1}-\gamma t x-(1-\gamma) t(1-x)<0 \Leftrightarrow x>x_{0}=\frac{s-p_{1}-(1-\gamma) t}{(2 \gamma-1) t} .
$$

For $p_{1}>s-\frac{t}{2}, x_{0}<\frac{1}{2}$, and profit is given by

$$
\pi=2 p_{1}\left(x_{0}-x_{W}\right)+2 p_{2} x_{W}=2 p_{1} \frac{s-p_{1}-(1-\gamma) t}{(2 \gamma-1) t}+\left(p_{2}-p_{1}\right)\left(1-\frac{p_{2}-p_{1}}{t(1-\gamma)}\right) .
$$

As before the optimal APD follows from $\frac{\partial \pi}{\partial p_{2}}=0$, leading $p_{2}-p_{1}=\frac{1}{2} t(1-\gamma)$. Substitution gives

$$
\pi=\frac{t}{4}(1-\gamma)+2 p_{1} \frac{s-p_{1}-(1-\gamma) t}{(2 \gamma-1) t}
$$

and

$$
\frac{\partial \pi}{\partial p_{1}}=\frac{2\left[s-2 p_{1}-(1-\gamma) t\right]}{(2 \gamma-1) t}
$$

Increasing $p_{1}$ beyond $s-\frac{t}{2}$ raises profits, i.e. $\left.\frac{\partial \pi}{\partial p_{1}}\right|_{p_{1}=s-\frac{t}{2}}>0$ if and only if $t-s-(1-\gamma) t>$ $0 \Leftrightarrow s<\gamma t$. Since Assumption 1 implies that $s>\gamma t$, it follows that increasing $p_{1}$ beyond $s-\frac{t}{2}$ cannot be profitable.

\section{Proof of Proposition 2}

\section{Existence}

To show that the price schedule $\left(p_{1}^{*}, p_{2}^{*}\right)$ given by (11) and (12) constitutes an equilibrium we need to show that there exists no profitable deviation to a price schedule $\left(p_{1}, p_{2}\right) \neq$ $\left(p_{1}^{*}, p_{2}^{*}\right)$. The proof proceeds as follows. In Step 1, we identify a subset of deviations (denoted as $\mathbf{P}_{a}$ in Figure 3) for which the profit of the deviating firm $\mathrm{A}$ is given by (8) and show that within this subset profits are strictly concave and hence maximized at $\left(p_{1}, p_{2}\right)=\left(p_{1}^{*}, p_{2}^{*}\right)$. In Steps $2-6$, we examine the remaining subsets of potential deviations for which the firm's profit takes a different form. 


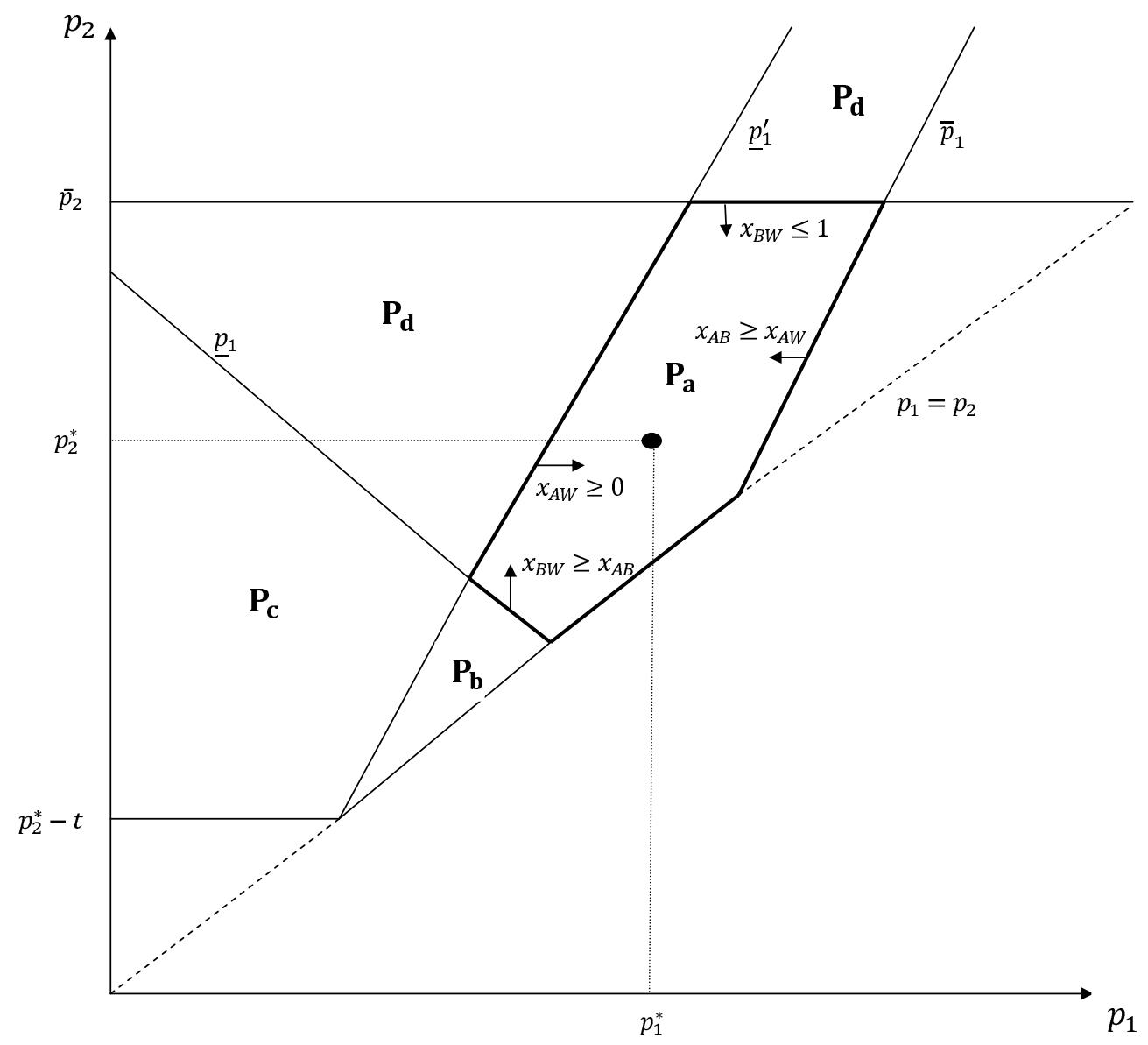

Figure 3: Potential deviations from the equilibrium price schedule $\left(p_{1}^{*}, p_{2}^{*}\right)$.

Step 1: Define the following set of deviations

$$
\mathbf{P}_{a} \equiv\left\{\left(p_{1}, p_{2}\right) \in \mathbf{R}_{+}^{2} \mid p_{1} \in\left[\max \left\{\underline{p}_{1}, \underline{p}_{1}^{\prime}\right\}, \bar{p}_{1}\right], p_{2} \in\left[p_{1}, \bar{p}_{2}\right]\right\}
$$

where the critical values satisfy

$$
\begin{aligned}
x_{B W} & \geq x_{A B} \Leftrightarrow p_{1} \geq \underline{p}_{1} \equiv \frac{\gamma p_{1}^{*}-(2 \gamma-1)\left(\gamma p_{2}^{*}+(1-\gamma) p_{2}\right)}{1-\gamma} \\
x_{A W} & \geq 0 \Leftrightarrow p_{1} \geq \underline{p}_{1}^{\prime} \equiv \gamma p_{2}+(1-\gamma) p_{2}^{*}-t(1-\gamma) \\
x_{A B} & \geq x_{A W} \Leftrightarrow p_{1} \leq \bar{p}_{1} \equiv \frac{(1-\gamma) p_{1}^{*}+(2 \gamma-1)\left(\gamma p_{2}+(1-\gamma) p_{2}^{*}\right)}{\gamma} \\
x_{B W} & \leq 1 \Leftrightarrow p_{2} \leq \bar{p}_{2} \equiv \frac{(1-\gamma) t-\gamma p_{2}^{*}+p_{1}^{*}}{1-\gamma}
\end{aligned}
$$

with $x_{A B}, x_{A W}$, and $x_{B W}$ defined by (4), (6), and (7) respectively. In our derivation of profits in (8) we assumed the deviation $\left(p_{1}, p_{2}\right)$ to be such that $x_{A B} \in\left(\min \left(\hat{x}_{A B}, 1-\right.\right.$ 
$\left.\left.\hat{x}_{A B}\right), \max \left(\hat{x}_{A B}, 1-\hat{x}_{A B}\right)\right)$ with $\hat{x}_{A B}$ defined in (5). It remains to show that (8) is also valid when this condition is not satisfied. For this purpose, suppose that $x_{A B}<\min \left(\hat{x}_{A B}, 1-\right.$ $\left.\hat{x}_{A B}\right)$. For consumers of type $x \in\left(x_{A B}, \min \left(\hat{x}_{A B}, 1-\hat{x}_{A B}\right)\right)$ the relevant comparison is then not between $V_{A B}$ and $U_{1, A}$ as in (6) but between $V_{A B}$ and $U_{1, B}$. But if waiting was optimal for such a type $x$, i.e. $V_{A B}>U_{1, B}$, then $U_{1, B}>U_{1, A}$ would imply that $V_{A B}>U_{1, A}$ contradicting the fact that in $\mathbf{P}_{a}$ it holds that $x_{A B} \geq x_{A W}$ and hence $x>x_{A W}$. Hence all types in $\left(x_{A B}, \min \left(\hat{x}_{A B}, 1-\hat{x}_{A B}\right)\right)$ will buy $B$ in period 1 and (8) remains valid. For the case where $x_{A B}>\max \left(\hat{x}_{A B}, 1-\hat{x}_{A B}\right)$ a similar argument applies. Hence for deviations in $\mathbf{P}_{a}$ profits are as defined in (8).

It is easy to see that $\left(p_{1}^{*}, p_{2}^{*}\right) \in \operatorname{int} \mathbf{P}_{a}$ is the unique solution to the first order conditions (9) and (10). To see that $\left(p_{1}^{*}, p_{2}^{*}\right)$ achieves not only a local but a global maximum in $\mathbf{P}_{a}$, consider the Hessian matrix given by

$$
H \equiv\left(\begin{array}{cc}
\frac{\partial^{2} \Pi_{A}}{\partial p_{1}^{2}} & \frac{\partial^{2} \Pi_{A}}{\partial p_{1} \partial p_{2}} \\
\frac{\partial^{2} \Pi_{A}}{\partial p_{2} \partial p_{1}} & \frac{\partial^{2} \Pi_{A}}{\partial p_{2}^{2}}
\end{array}\right)=\left(\begin{array}{cc}
-\frac{\gamma}{t(2 \gamma-1)(1-\gamma)} & \frac{\gamma}{t(1-\gamma)} \\
\frac{\gamma}{t(1-\gamma)} & -\frac{\gamma^{2}+(1-\gamma)^{2}}{t(1-\gamma)}
\end{array}\right) .
$$

The $i$-th leading principal minor of this Hessian, denoted by $H(i)$, is given by $H(1)=$ $\frac{\partial^{2} \Pi_{A}}{\partial p_{1}^{2}}=-\frac{\gamma}{t(2 \gamma-1)(1-\gamma)}<0$ and $H(2)=\frac{\partial^{2} \Pi_{A}}{\partial p_{1}^{2}} \frac{\partial^{2} \Pi_{A}}{\partial p_{2}^{2}}-\left(\frac{\partial^{2} \Pi_{A}}{\partial p_{1} \partial p_{2}}\right)^{2}=\frac{\gamma}{t^{2}(1-\gamma)(2 \gamma-1)}>0$. Hence, $H$ is negative definite and so the profit function $\Pi_{A}$ is strictly concave in $\mathbf{P}_{a}$.

Step 2: Consider the set of deviations

$$
\mathbf{P}_{b} \equiv\left\{\left(p_{1}, p_{2}\right) \in \mathbf{R}_{+}^{2} \mid p_{1} \in\left[\underline{p}_{1}^{\prime}, \underline{p}_{1}\right], p_{2} \geq p_{1}\right\}
$$

By definition of the threshold $\underline{p}_{1}$ it holds in $\mathbf{P}_{b}$ that $x_{B W}<x_{A B}$. Hence for $x \in$ $\left[\max \left(\hat{x}_{A B}, 1-\hat{x}_{A B}\right), x_{A B}\right]$ the relevant comparison is between $V_{B A}$ and $U_{1, A}$ :

$$
U_{1, A}>V_{B A} \Leftrightarrow x<x_{A W}^{\prime} \equiv \frac{1}{2}+\frac{\gamma p_{2}^{*}+(1-\gamma) p_{2}-p_{1}}{2 \gamma t}
$$

where $x_{A W}^{\prime} \leq x_{A B}$. Consumers in $\left[x_{A W}, x_{A W}^{\prime}\right]$ buy $\mathrm{A}$ in period 1 while the remaining consumers wait. Firm $B$ has no customers in period 1. Hence in $\mathbf{P}_{b}$ the profit of firm $A$ is given by

$$
\Pi_{A}=p_{1}\left(x_{A W}^{\prime}-x_{A W}\right)+p_{2}\left[\gamma x_{A W}+(1-\gamma)\left(1-x_{A W}^{\prime}\right)\right]
$$

We now show that in $\mathbf{P}_{b}, \Pi_{A}$ is strictly increasing in $p_{1}$ and $\left.\Pi_{A}\right|_{p_{1}=p_{2}}$ is strictly increasing in $p_{2}$. By continuity, this implies that all deviations in $\mathbf{P}_{b}$ are dominated by a deviation 
in $\mathbf{P}_{a}$ (see figure). For any $\left(p_{1}, p_{2}\right) \in \mathbf{P}_{b}$, we have

$$
\begin{aligned}
\gamma(1-\gamma) t \frac{\partial \Pi_{A}}{\partial p_{1}} & =-p_{1}+\gamma(1-\gamma) p_{2}^{*}+\left((1-\gamma)^{2}+\gamma^{2}\right) p_{2} \\
& \geq-\min \left\{\underline{p}_{1}, p_{2}\right\}+\gamma(1-\gamma) p_{2}^{*}+\left((1-\gamma)^{2}+\gamma^{2}\right) p_{2} \\
& \geq \gamma\left(\gamma p_{2}^{*}-p_{1}^{*}\right)=\frac{(1-\gamma)^{2} \gamma t}{-4 \gamma^{2}+7 \gamma-1}>0
\end{aligned}
$$

where the second inequality follows from the fact that $\underline{p}_{1} \leq p_{2} \Leftrightarrow p_{2} \geq \frac{p_{1}^{*}-(2 \gamma-1) p_{2}^{*}}{2(1-\gamma)}$. Moreover, for any $\left(p_{1}, p_{2}\right) \in \mathbf{P}_{b}$ such that $p_{1}=p_{2}$ it holds that

$$
\left.\frac{\partial \Pi_{A}}{\partial p_{2}}\right|_{p_{1}=p_{2}}=\frac{-2 p_{2}+p_{2}^{*}+t}{2 t} \geq \frac{-p_{1}^{*}+\gamma p_{2}^{*}+(1-\gamma) t}{2 t(1-\gamma)}=\frac{\gamma(3-2 \gamma)}{-4 \gamma^{2}+7 \gamma-1}>0
$$

where the first inequality follows from $p_{2} \leq \frac{p_{1}^{*}-(2 \gamma-1) p_{2}^{*}}{2(1-\gamma)}$. This completes the proof of Step 2 .

Step 3: Consider the set of deviations

$$
\mathbf{P}_{c} \equiv\left\{\left(p_{1}, p_{2}\right) \in \mathbf{R}_{+}^{2} \mid p_{1} \leq \min \left\{\underline{p}_{1}^{\prime}, \underline{p}_{1}\right\}, p_{2} \geq p_{2}^{*}-t\right\}
$$

The only difference to the previous case is the fact that for $p_{1} \leq \underline{p}_{1}^{\prime}$ it no longer holds that $x_{A W}>0$. The profit of firm $A$ is thus given by

$$
\Pi_{A}=p_{1} x_{A W}^{\prime}+p_{2}(1-\gamma)\left(1-x_{A W}^{\prime}\right)
$$

We now show that in $\mathbf{P}_{c}, \Pi_{A}$ is strictly increasing in $p_{1}$. By continuity, this implies that all deviations in $\mathbf{P}_{c}$ are dominated by a deviation in $\mathbf{P}_{b} \cup \mathbf{P}_{d}$ (see figure). For any $\left(p_{1}, p_{2}\right) \in \mathbf{P}_{c}$, we have

$$
\frac{\partial \Pi_{A}}{\partial p_{1}}=\frac{\gamma t-2 p_{1}+\gamma p_{2}^{*}+2(1-\gamma) p_{2}}{2 \gamma t}
$$

Since $\frac{\partial \Pi_{A}}{\partial p_{1}}$ is decreasing in $p_{1}$ and increasing in $p_{2}$ it becomes minimal on the boundary $\mathbf{P}_{b} \cap \mathbf{P}_{c}$. We have

$$
\left.\frac{\partial \Pi_{A}}{\partial p_{1}}\right|_{p_{1}=\underline{p}_{1}^{\prime}}=\frac{(2-\gamma) t+2(1-2 \gamma) p_{2}-(2-3 \gamma) p_{2}^{*}}{2 \gamma t}
$$

Since $\left.\frac{\partial \Pi_{A}}{\partial p_{1}}\right|_{p_{1}=\underline{p}_{1}^{\prime}}$ is decreasing in $p_{2}$ it becomes minimal at the point $\mathbf{P}_{a} \cap \mathbf{P}_{b} \cap \mathbf{P}_{c}$ where

$$
\frac{\partial \Pi_{A}}{\partial p_{1}}=\frac{-2 \gamma^{3}+\gamma^{2}+4 \gamma-1}{(3 \gamma-1)\left(-4 \gamma^{2}+7 \gamma-1\right)}>0
$$


This shows that $\frac{\partial \Pi_{A}}{\partial p_{1}}>0$ in the entire set $\mathbf{P}_{c}$ which completes the proof of Step 3.

Step 4: Consider the set of deviations

$$
\mathbf{P}_{d} \equiv\left\{\left(p_{1}, p_{2}\right) \in \mathbf{R}_{+}^{2} \mid p_{1} \in\left[\min \left\{0, \underline{p}_{1}\right\}, \underline{p}_{1}^{\prime}\right], p_{2} \leq \bar{p}_{2}\right\}
$$

In comparison to the set $\mathbf{P}_{a}$ the only difference is that in $\mathbf{P}_{d}$ it no longer holds that $x_{A W}>0$. Firm $A$ 's profit is thus given by

$$
\Pi_{A}=p_{1} x_{A B}+p_{2}(1-\gamma)\left(1-x_{B W}\right)
$$

For any $\left(p_{1}, p_{2}\right) \in \mathbf{P}_{d}$, we have

$$
\frac{\partial \Pi_{A}}{\partial p_{1}}=\frac{(2 \gamma-1) t-2 p_{1}+p_{1}^{*}}{2(2 \gamma-1) t}>\frac{(2 \gamma-1) t-2 \underline{p}_{1}^{\prime}+p_{1}^{*}}{2(2 \gamma-1) t} .
$$

To identify the sign of the R.H.S. of the last inequality, observe that

$$
\begin{gathered}
(2 \gamma-1) t-2 \underline{p}_{1}^{\prime}+p_{1}^{*}=(2 \gamma-1) t-2\left(\gamma p_{2}+(1-\gamma)\left(p_{2}^{*}-t\right)\right)+p_{1}^{*}>0 \\
\Leftrightarrow p_{2}<\frac{p_{1}^{*}+t-2(1-\gamma) p_{2}^{*}}{2 \gamma} \equiv \tilde{p}_{2} \in\left(p_{2}^{*}, \bar{p}_{2}\right) .
\end{gathered}
$$

Hence, for $p_{2}<\tilde{p}_{2}$, profit is strictly increasing in $p_{1}$ so that a deviation $\left(p_{1}, p_{2}\right) \in \mathbf{P}_{d}$ is dominated by a deviation in $\mathbf{P}_{a} \cap \mathbf{P}_{d}$. For $p_{2} \geq \tilde{p}_{2}$, observe that

$$
\frac{\partial \Pi_{A}}{\partial p_{2}}=\frac{(1-\gamma) t-\gamma p_{2}^{*}-2(1-\gamma) p_{2}+p_{1}^{*}}{2 t} \leq \frac{(1-\gamma) t-\gamma p_{2}^{*}-2(1-\gamma) \tilde{p}_{2}+p_{1}^{*}}{2 t},
$$

with the last term being negative if and only if $2(1-\gamma)\left(2 \gamma^{2}+1\right)>0$. Hence, profit is strictly decreasing in $p_{2} \geq \tilde{p}_{2}$. Since

$$
\left.\frac{\partial \prod_{A}}{\partial p_{1}}\right|_{p_{1}=\underline{p}_{1}}>0 \Leftrightarrow 4 \gamma(1-\gamma)^{2}>0
$$

this implies that for $p_{2}>\tilde{p}_{2}$, profit is smaller than the one evaluated at the intersection of $\tilde{p}_{2}$ and $\underline{p}_{1}$. It thus remains to show that this profit is smaller than the equilibrium profit. This is indeed the case since

$$
\Pi_{A}\left(p_{1}^{*}, p_{2}^{*}\right)-\Pi_{A}\left(\underline{p}_{1}, \tilde{p}_{2}\right)=\frac{t(1-\gamma)^{2}[4 \gamma(2 \gamma-1)(1-\gamma)+1]}{2\left(-4 \gamma^{2}+7 \gamma-1\right)^{2}}>0 .
$$

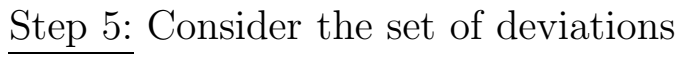

$$
\mathbf{P}_{e} \equiv\left\{\left(p_{1}, p_{2}\right) \in \mathbf{R}_{+}^{2} \mid p_{1} \in\left[\underline{p}_{1}^{\prime}, \bar{p}_{1}\right] \cdot p_{2} \geq \bar{p}_{2}\right\}
$$


In comparison to the set $\mathbf{P}_{a}$ the only difference is that in $\mathbf{P}_{e}$ it no longer holds that $x_{B W}<1$. Firm $A$ 's profit is thus given by

$$
\Pi_{A}=p_{1}\left(x_{A B}-x_{A W}\right)+p_{2} \gamma x_{A W} .
$$

Differentiation yields

$$
\frac{\partial \Pi_{A}}{\partial p_{2}}=\frac{\gamma\left[t(1-\gamma)-2 \gamma p_{2}-(1-\gamma) p_{2}^{*}+2 p_{1}\right]}{2 t(1-\gamma)}
$$

Since $\frac{\partial \Pi_{A}}{\partial p_{2}}$ is increasing in $p_{1}$ and decreasing in $p_{2}$ it it becomes maximal at the intersection of $\bar{p}_{1}$ and $\bar{p}_{2}$. We have

$$
\begin{aligned}
\left.\frac{\partial \prod_{A}}{\partial p_{2}}\right|_{p_{1}=\bar{p}_{1}, p_{2}=\bar{p}_{2}}<0 & \Leftrightarrow 0<\gamma(1-\gamma) t+\left(\gamma^{2}-5 \gamma+2\right) p_{2}^{*}+2(2 \gamma-1) p_{1}^{*} \\
& \Leftrightarrow 4 \gamma(1-\gamma)\left(-\gamma^{2}+\gamma+1\right)>0 .
\end{aligned}
$$

Hence, any deviation in when $\mathbf{P}_{e}$ is dominated by a deviation in $\mathbf{P}_{a} \cap \mathbf{P}_{e}$, i.e. no deviation in $\mathbf{P}_{e}$ can be profitable.

Step 6: For all remaining areas it is easy to see that any deviation is dominated by a deviation already contained in $\bigcup_{i=a}^{e} \mathbf{P}_{i}$. If $p_{2}<p_{2}^{*}-t$ then all consumers prefer $A$ over $B$ in period 2. Firm $A$ can achieve a higher profit by deviating instead to $\left(p_{1}, p_{2}\right)=\left(p_{2}^{*}-t, p_{2}^{*}-t\right) \in \mathbf{P}_{b} \cap \mathbf{P}_{c}$. If $\left(p_{1}, p_{2}\right)$ is such that $p_{1}>\bar{p}_{1}$ then $x_{A B}<x_{A W}$, i.e. firm $A$ makes no sales in period 1. Moreover, the thresholds $x_{B W}$ and $x_{B W}^{\prime}$ determining second period demands are independent of $p_{1}$ since they are based on a comparison of $p_{2}$ and $p_{2}^{*}$ with firm $B$ 's first period price $p_{1}^{*}$. Hence firm $A$ can achieve the same profit by deviating to $\left(\bar{p}_{1}, p_{2}\right) \in \mathbf{P}_{a} \cup \mathbf{P}_{d}$. Finally, if $\left(p_{1}, p_{2}\right)$ is such that $p_{1}<\underline{p}_{1}^{\prime}$ and $p_{2}>\bar{p}_{2}$ then all consumers purchase in period 1. Hence profit in this region is independent of $p_{2}$ and needs to be considered only on the boundary shared with $\mathbf{P}_{d} \cup \mathbf{P}_{e}$.

In summary, we have shown that there does not exist a profitable deviation from the price schedule $\left(p_{1}^{*}, p_{2}^{*}\right)$. Hence both firms choosing $\left(p_{1}^{*}, p_{2}^{*}\right)$ constitutes an equilibrium.

\section{Uniform pricing}

In order to prove that firms implement an APD in any symmetric equilibrium we now show that uniform pricing cannot be an equilibrium. Suppose that firm $B$ sets a uniform price $p_{1}^{u}=p_{2}^{u}$ and consider a deviation by firm $A$ to $\left(p_{1}, p_{2}\right)$ with $p_{1}<p_{2}=p_{2}^{u}$. The profit of the deviating firm is then given by

$$
\Pi_{A}=p_{1}\left(x_{A W}^{\prime}-x_{A W}\right)+p_{2}\left[\gamma x_{A W}+(1-\gamma)\left(1-x_{A W}^{\prime}\right)\right]
$$


with $x_{A W}$ and $x_{A W}^{\prime}$ defined in (6) and (34). Note that we have

$$
\left.\frac{\partial \Pi_{A}}{\partial p_{1}}\right|_{p_{1}=p_{1}^{u}}=-\frac{p_{2}^{u}}{t}<0 .
$$

Hence lowering the first period price is profitable and $p_{1}^{u}=p_{2}^{u}$ cannot be an equilibrium.

\section{Proof of Corollary 2}

The equilibrium prices satisfy:

$$
\begin{gathered}
\frac{d p_{1}^{*}}{d \gamma}=\left[2 \gamma^{2}+(1-\gamma)^{2}\right] \frac{3 t\left(\sigma^{*}\right)^{2}}{2 \gamma^{2}}>0, \frac{d p_{2}^{*}}{d \gamma}=\left[2 \gamma^{2}+(1-\gamma)^{2}\right] \frac{t\left(\sigma^{*}\right)^{2}}{\gamma^{2}}>0, \\
\frac{d\left(p_{2}^{*}-p_{1}^{*}\right)}{d \gamma}=-\left[2 \gamma^{2}+(1-\gamma)^{2}\right] \frac{t\left(\sigma^{*}\right)^{2}}{2 \gamma^{2}}<0 .
\end{gathered}
$$

For the fraction of customers each firm serves in advance, $\sigma^{*}$, we find

$$
\frac{d \sigma^{*}}{d \gamma}=\left(4 \gamma^{2}-1\right) \frac{\left(\sigma^{*}\right)^{2}}{2 \gamma^{2}}>0 \quad \forall \gamma \in\left(\frac{1}{2}, 1\right)
$$

The profit of a firm is given by

$$
\Pi^{*}=p_{1}^{*} \sigma^{*}+p_{2}^{*}\left(1-\sigma^{*}\right)=\frac{t\left(\sigma^{*}\right)^{2}}{8 \gamma^{2}}\left(-8 \gamma^{3}+21 \gamma^{2}-10 \gamma+1\right)>0 .
$$

It satisfies:

$$
\begin{gathered}
\frac{d \Pi^{*}}{d \gamma}=\left(56 \gamma^{4}+28 \gamma^{3}-24 \gamma^{2}+11 \gamma-1\right) \frac{t\left(\sigma^{*}\right)^{2}}{2 \gamma^{2}} \\
>\left(4 \gamma^{2}+11 \gamma-1\right) \frac{t\left(\sigma^{*}\right)^{2}}{2 \gamma^{2}}>0 \quad \forall \gamma \in\left(\frac{1}{2}, 1\right) .
\end{gathered}
$$

This completes the proof of Corollary 2 .

\section{Proof of Proposition 3}

Consider

$$
\Delta p^{*}-\Delta p^{M}=p_{2}^{*}-p_{1}^{*}-\left(p_{2}^{M}-p_{1}^{M}\right)=(1-\gamma) t\left[\sigma^{*}-\frac{1}{2}\right] .
$$

Corollary 2 has shown that $\sigma^{*}$ is increasing in $\gamma \in\left(\frac{1}{2}, 1\right)$. It converges to $\frac{2}{3}$ for $\gamma \rightarrow \frac{1}{2}$. It therefore holds that $\sigma^{*}>\frac{1}{2}$ and hence $p_{2}^{*}-p_{1}^{*}-\left(p_{2}^{M}-p_{1}^{M}\right)>0$ for all $\gamma \in\left(\frac{1}{2}, 1\right)$. Finally, $\frac{\Delta p^{*}}{p_{1}^{*}}>\frac{\Delta p^{M}}{p_{1}^{M}}$ follows immediately from $\Delta p^{*}>\Delta p^{M}$ and $p_{1}^{*}<p_{1}^{M}$ (Proposition 5). 


\section{Proof of Proposition 4}

Since $p_{1}^{*}$ and $p_{2}^{*}$ are both proportional to $t$ and $\sigma^{*}$ is independent of $t, G^{*}$ is independent of $t$. In contrast,

$$
\frac{d G^{M}}{d t}=\frac{(1-\gamma) s}{4\left[s-\frac{t}{4}(1+\gamma)\right]^{2}}>0
$$

with $\lim _{t \rightarrow 0} G^{M}=0$. Hence there exists a threshold $t^{G i n i}>0$ such that $G^{*}>G^{M}$ if and only if $t<t^{\text {Gini }}$. This threshold is readily calculated from $G^{M}=G^{*}$ and given by

$$
t^{\text {Gini }}=\frac{32 \gamma^{2}\left(4 \gamma^{2}-5 \gamma+1\right)}{132 \gamma^{4}-227 \gamma^{3}+103 \gamma^{2}-17 \gamma+1} s .
$$

Moreover

$$
\frac{d t^{\text {Gini }}}{d \gamma}=-\frac{64 \gamma s\left(124 \gamma^{5}-280 \gamma^{4}+246 \gamma^{3}-93 \gamma^{2}+16 \gamma-1\right)}{\left(132 \gamma^{4}-227 \gamma^{3}+103 \gamma^{2}-17 \gamma+1\right)^{2}}<0
$$

since $124 \gamma^{5}-280 \gamma^{4}+246 \gamma^{3}-93 \gamma^{2}+16 \gamma-1>0$ for all $\gamma \in\left(\frac{1}{2}, 1\right)$.

\section{Proof of Proposition 5}

The fact that $p_{1}^{M}-p_{1}^{*}=s-\frac{t}{2}-p_{1}^{*}>0$ follows from Assumption 1 which guarantees that the lowest consumer type $x=\frac{1}{2}$ obtains positive utility from purchasing at the equilibrium price $p_{1}^{*}$. It remains to consider

$$
p_{2}^{M}-p_{2}^{*}=s-\gamma \frac{t}{2}-\sigma^{*}\left(\frac{3}{2}-\frac{1}{2 \gamma}\right) t=s-\frac{t \sigma^{*}}{4 \gamma}\left(-4 \gamma^{3}+7 \gamma^{2}+5 \gamma-2\right) .
$$

Since $5 \gamma>2$ and $4 \gamma<7$ for all $\gamma \in\left(\frac{1}{2}, 1\right), p_{2}^{M}-p_{2}^{*}$ is linearly decreasing in $t$. It becomes zero at

$$
t^{S p o t}(\gamma) \equiv \frac{-8 \gamma^{2}+14 \gamma-2}{-4 \gamma^{3}+7 \gamma^{2}+5 \gamma-2} s
$$

It is easy to see that

$$
\frac{d t^{\text {Spot }}}{d \gamma}=-\frac{2\left(16 \gamma^{4}-56 \gamma^{3}+81 \gamma^{2}-30 \gamma+9\right)}{\left(4 \gamma^{3}-7 \gamma^{2}-5 \gamma+2\right)^{2}}<0
$$

for all $\gamma \in\left(\frac{1}{2}, 1\right)$. Finally, define $\bar{t} \equiv \frac{-8 \gamma^{2}+14 \gamma-2}{9 \gamma-3} s$. For a given $s>0, \bar{t}$ is the maximum value of $t$ for which Assumption 1 is satisfied. Note that $t^{\text {Spot }}<\bar{t}$ since

$$
-4 \gamma^{3}+7 \gamma^{2}+5 \gamma-2>9 \gamma-3 \Leftrightarrow(1-\gamma)\left(4 \gamma^{2}-3 \gamma+1\right)>0
$$

for all $\gamma \in\left(\frac{1}{2}, 1\right)$. This shows that $t>t^{\text {Spot }}$ is never in conflict with Assumption 1 . 


\section{Proof of Proposition 6}

Consider

$$
\begin{array}{r}
\frac{d\left(W^{*}-W^{M}\right)}{d \gamma}=\frac{t}{8}\left[4\left(\sigma^{*}\right)^{2}-1-8(1-\gamma) \sigma^{*} \frac{d \sigma^{*}}{d \gamma}\right] \\
=\frac{t}{8}\left(\frac{8 \gamma^{3}-2 \gamma^{2}-6 \gamma+4}{\gamma^{2}}\left(\sigma^{*}\right)^{3}-1\right)>0 \\
\Leftrightarrow f(\gamma) \equiv 64 \gamma^{6}-336 \gamma^{5}+700 \gamma^{4}-527 \gamma^{3}+111 \gamma^{2}+11 \gamma+1>0 .
\end{array}
$$

To prove the last inequality, note that if there exists some $\gamma \in\left(\frac{1}{2}, 1\right)$ such that $f(\gamma)<0$, then, since $\lim _{\gamma \rightarrow \frac{1}{2}} f(\gamma)=\frac{21}{8}>0$ and $\lim _{\gamma \rightarrow 1} f(\gamma)=24>0$, we must have at least two values of $\gamma \in\left(\frac{1}{2}, 1\right)$ that satisfies $f(\gamma)=0$. Now, collecting terms, the function $f$ takes the form $f=a z^{2}+b z+c$ with $z \equiv 1-\gamma$, and

$$
\begin{aligned}
a & \equiv 4 \gamma^{2}\left(16 \gamma^{2}-52 \gamma+55\right)>0 \\
b & \equiv-121 \gamma^{2}<0 \\
c & \equiv 12 \gamma^{2}+11 \gamma+1>0
\end{aligned}
$$

Any solution $z \in\left(0, \frac{1}{2}\right)$ of $f=0$ must satisfy

$$
z=\frac{-b \pm \sqrt{b^{2}-4 a c}}{2 a}
$$

Assuming $b^{2} \geq 4 a c$ (which is required for the existence of a solution) the larger of the solutions, denoted by $z_{+}$, must therefore satisfy

$z_{+}=\frac{-b+\sqrt{b^{2}-4 a c}}{2 a}<\frac{1}{2} \Leftrightarrow(-b)^{2}<\left(a-\sqrt{b^{2}-4 a c}\right)^{2} \Leftrightarrow 0<a-4 c-2 \sqrt{b^{2}-4 a c} .(74)$

Observe that

$$
c-\frac{a}{4}=-16 \gamma^{4}+52 \gamma^{3}-43 \gamma^{2}+11 \gamma+1>-16 \gamma^{4}+48 \gamma^{3}-44 \gamma^{2}+12 \gamma+1>0
$$

for all $\gamma \in\left(\frac{1}{2}, 1\right)$. The first inequality holds since $4 \gamma^{3}+\gamma^{2}-\gamma>0$ for all $\gamma \in\left(\frac{1}{2}, 1\right)$. To see that the last term is positive note that its derivative is given by $4(3-4 \gamma)\left(4 \gamma^{2}-6 \gamma+1\right)$. Since $4 \gamma^{2}-6 \gamma+1=2(1-\gamma)(1-2 \gamma)-1<0$ for all $\gamma \in\left(\frac{1}{2}, 1\right)$ there exists a unique minimum at $\gamma=\frac{3}{4}$. Its value is given by $\frac{7}{16}>0$.

Hence, the inequality (74) cannot hold for $\gamma \in\left(\frac{1}{2}, 1\right)$. This implies that there is no $\gamma \in\left(\frac{1}{2}, 1\right)$ that satisfies $f(\gamma)=0$. Hence we must have $f(\gamma)>0$ for all $\gamma \in\left(\frac{1}{2}, 1\right)$. 


\section{Proof of Proposition 7}

Part 1: Proposition 5 has shown that for $t<t^{\text {Spot }}$ competition reduces prices in both periods. Hence, in this case, all consumers benefit from competition independently of their preference intensity. Suppose $t>t^{\text {Spot }}$, so that $p_{2}^{*}>p_{2}^{M}$. Under monopoly, a consumer with $\sigma=\frac{1}{2}$ is indifferent between buying in advance and waiting, so that $p_{2}^{M}-p_{1}^{M}-t(1-\gamma) \sigma=0$ and hence $p_{2}^{M}-p_{1}^{*}-t(1-\gamma) \sigma>0$. Under competition, a consumer with $\sigma=\sigma^{*}$ is indifferent between buying in advance and waiting, so that $p_{2}^{*}-p_{1}^{*}-t(1-\gamma) \sigma=0$ and thus $p_{2}^{M}-p_{1}^{*}-t(1-\gamma) \sigma<0$. Since $p_{2}^{M}-p_{1}^{*}-t(1-\gamma) \sigma$ is strictly decreasing in $\sigma$ it follows that there exists a $\sigma^{C S}(t) \equiv \frac{p_{2}^{M}-p_{1}^{*}}{t(1-\gamma)} \in\left(\frac{1}{2}, \sigma^{*}\right)$ such that $C S^{*}(\sigma)>C S^{M}(\sigma)>0$ if and only if $\sigma<\sigma_{C S}(t) . \sigma_{C S}(t)$ is decreasing in $t$ since $p_{2}^{M}-p_{1}^{*}$ is decreasing.

Part 2: Substitution of prices into (20) gives

$$
\Sigma C S^{*}-\Sigma C S^{M}=s-t\left[\frac{1}{8}+\frac{3}{8} \gamma+\left(\frac{3}{2}-\frac{1}{2 \gamma}\right) \sigma^{*}-\frac{1}{2}(1-\gamma)\left(\sigma^{*}\right)^{2}\right] .
$$

$\Sigma C S^{*}-\Sigma C S^{M}$ is strictly decreasing in $t$ since from $\sigma^{*} \in\left(\frac{2}{3}, 1\right)$ it follows that

$$
\begin{aligned}
\frac{1}{8}+\frac{3}{8} \gamma+\left(\frac{3}{2}-\frac{1}{2 \gamma}\right) \sigma^{*}-\frac{1}{2}(1-\gamma)\left(\sigma^{*}\right)^{2} & >\frac{1}{8}+\frac{3}{8} \gamma+\left(\frac{3}{2}-\frac{1}{2 \gamma}\right) \frac{2}{3}-\frac{1}{2}(1-\gamma) \\
& =\frac{7 \gamma^{2}+3 \gamma-2}{8 \gamma}>0
\end{aligned}
$$

for all $\gamma \in\left(\frac{1}{2}, 1\right)$. Hence

$$
t^{C S}(\gamma) \equiv s\left[\frac{1}{8}+\frac{3}{8} \gamma+\left(\frac{3}{2}-\frac{1}{2 \gamma}\right) \sigma^{*}-\frac{1}{2}(1-\gamma)\left(\sigma^{*}\right)^{2}\right]^{-1}
$$

is such that $\Sigma C S^{*}-\Sigma C S^{M}>(<) 0$ if and only if $t<(>) t^{C S}(\gamma)$. Define $\bar{t} \equiv \frac{-8 \gamma^{2}+14 \gamma-2}{9 \gamma-3} s$. For a given $s>0, \bar{t}$ is the maximum value of $t$ for which Assumption 1 is satisfied. Note that $t^{C S}<\bar{t}$ since for $t \rightarrow \bar{t}$ we have $p_{1}^{*} \rightarrow p_{1}^{M}$ and $p_{2}^{*}>p_{2}^{M}$ which implies that $\Sigma C S^{*}<$ $\Sigma C S^{M}$. This shows that $t>t^{C S}$ is never in conflict with Assumption 1. Similarly, $t^{C S}>t^{\text {Spot }}$, since for $t \leq t^{\text {Spot }}$ we have $p_{1}^{*}<p_{1}^{M}$ and $p_{2}^{*}<p_{2}^{M}$ which implies that $\Sigma C S^{*}>\Sigma C S^{M}$. Finally, to see that $t^{C S}(\gamma)$ is decreasing in $\gamma$ note that $\frac{d \sigma^{*}}{d \gamma}>0$ by Corollary 2 and

$$
\frac{d}{d \gamma}\left[(1-\gamma)\left(\sigma^{*}\right)^{2}\right]=\frac{\left(\sigma^{*}\right)^{3}}{2 \gamma^{2}}\left(-4 \gamma^{3}+\gamma^{2}+3 \gamma-2\right)<0
$$

for all $\gamma \in\left(\frac{1}{2}, 1\right)$. 


\section{References}

[1] Alexander, A., J. (2000) Japan's Aviation Industry: Deregulation Advances on Broad Front, Japan Economic Institute Report 21, available at http://www.jei.org/Restricted/JEIR00/0021f.html.

[2] Armstrong, M., Vickers, J. (2001) Competitive Price Discrimination, RAND Journal of Economics 32, pp. 579-605.

[3] Asplund, M., Eriksson, R., N. Strand. (2008) Price Discrimination in Oligopoly: Evidence from Regional Newspapers, Journal of Industrial Economics 56 (2), pp. 333-346.

[4] Bar Isaac, H., Caruana, G., Cuñat, V. (2010) Information Gathering and Marketing, Journal of Economics and Management Strategy 19 (2), pp. 375-401.

[5] Bulow, J. I. (1982) 'Durable Goods Monopolists', Journal of Political Economy, vol. 90(2), pp. 314-332.

[6] Borenstein, S. (1985) Price Discrimination in Free-Entry Markets, RAND Journal of Economics, 16(3), pp. 380-397.

[7] Borenstein, S. (1989) Hubs and High Fares: Dominance and Market Power in the U.S. Airline Industry, RAND Journal of Economics 20(3), pp. 344-65.

[8] Borenstein, S., Rose., N. (1994) Competition and Price Dispersion in the U.S. Airline Industry, Journal of Political Economy 102 (4), pp. 653-83.

[9] Busse, M., Rysman, M. (2005) Competition and Price Discrimination in Yellow Pages Advertising, RAND Journal of Economics, 36(2), pp. 378-390.

[10] Chen, Y. (1997) Paying Customers to Switch, Journal of Economics and Management Strategy 6, pp. 877-897.

[11] Corts, K., S. (1998) Third-Degree Price Dsicrimination in Oligopoly: All-Out Competition and Strategic Commitment, RAND Journal of Economics 29, pp. 306-323.

[12] Courty, P., Li, H. (2000) Sequential Screening, Review of Economic Studies 67(4), pp. $697-717$.

[13] Courty, P. (2003) Ticket Pricing under Demand Uncertainty, Journal of Law and Economics 46, pp. 627-652. 
[14] Dai, M., Liu, Q., Serfes, K. (2014) Is the Effect of Competition on Price Dispersion Non-Monotonic? Evidence form the U.S. Airline Industry, Review of Economics and Statistics, forthcoming.

[15] Dana Jr., J. D. (1998) Advance Purchase Discounts and Price Discrimination in Competitive Markets, Journal of Political Economy, vol. 106, pp. 395-422.

[16] Dana Jr., J. D. (1999) Equilibrium Price Dispersion under Demand Uncertainty: The Roles of Costly Capacity and Market Structure, RAND Journal of Economics, vol. 30(4), pp. 632-660.

[17] DeGraba, P. (1995) Buying Frenzies and Seller Induced Excess Demand, RAND Journal of Economics, 26(2), pp. 331-342.

[18] Fudenberg, D., Tirole, J. (2000) Customer Poaching and Brand Switching, RAND Journal of Economics 31, pp. 634-657.

[19] Gaggero, A. A., Piga, C. A. (2011) Airline Market Power and Intertemporal Price Dispersion, Journal of Industrial Economics 59(4), pp. 552-577.

[20] Gale, I. (1993) Price Dispersion in a Market with Advance-Purchase, Review of Industrial Organization 8, pp. 451-464.

[21] Gale, I., Holmes, T. (1993) Advance-Purchase Discounts and Monopoly Allocation of Capacity, American Economic Review 83(1), pp. 135-146.

[22] Gerardi, K., Shapiro, A. H. (2009) Does Competition Reduce Price Discrimination? New Evidence from the Airline Industry, Journal of Political Economy 117(1) pp. $1-34$.

[23] Holmes T. (1989) The Effects of Third-Degree Price Discrimination in Oligopoly, American Economic Review 79, pp. 244-250.

[24] Lewis, T., Sappington, D. (1994) Supplying Information to Facilitate Price Discrimination, International Economic Review 35(2), pp. 309-327.

[25] Möller, M., Watanabe, M. (2010) Advance Purchase Discounts versus Clearance Sales, Economic Journal 547, pp. 1125-1148.

[26] Moon, S., Watanabe, M. (2013) Refundability and Price: Empirical Analysis of the Airline Industry, mimeo. 
[27] Nocke, V., Peitz, M., Rosar, F. (2011) Advance-Purchase Discounts as a Price Discrimination Device, Journal of Economic Theory 146(1), pp. 141-162.

[28] Rochet, J., C., Stole, L., A. (2002) Nonlinear Pricing with Random Participation. Review of Economic Studies 69(1), pp. 277-311.

[29] Stavins, J. (1996) Price Discrimination in the Airline Market: The Effect of Market Concentration, Review of Economics and Statistics 83(1), pp. 200-202.

[30] Stole, L., A. (1995) Nonlinear Pricing and Oligopoly. Journal of Economics and Management Strategy 4(4), pp. 529-62.

[31] Stole, L., A. (2007) Price Discrimination and Competition, Handbook of Industrial Organization Vol. 3, Ch. 34, pp. 2221-2299.

[32] Thisse, J.-F., Vives, X. (1988) On the Strategic Choice of Spatial Price Policy, American Economic Review 78(1), pp. 122-137.

[33] Villas-Boas, J., M. (1999) Dynamic Competition with Customer Recognition, RAND Journal of Economics, 30, pp. 604-631. 